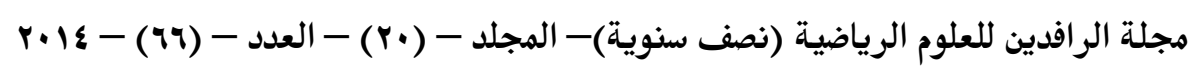

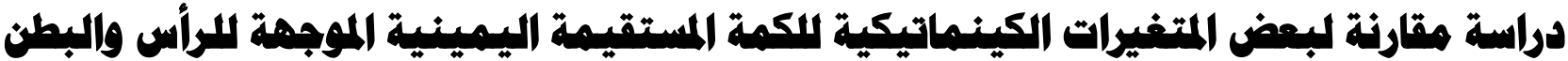 في رباضة الباكمة

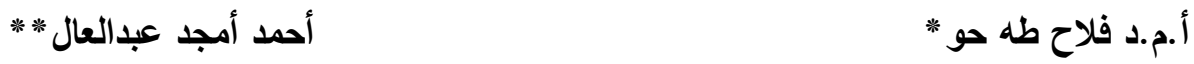

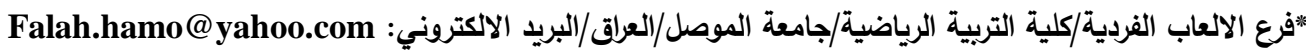

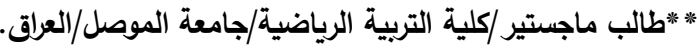

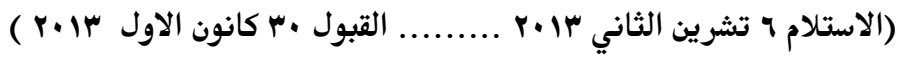

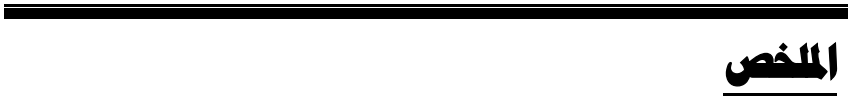

$$
\text { هدف البحث الى ما يأتي: }
$$

-التعرف على قيم بعض المتغيرات الكينماتيكية للكمة المستقيمة اليمينية الموجهة إلى الرأس. -التعرف على قيم بعض المتغيرات الكينماتيكية للكمة المستقيمة اليمينية الموجهة إلى البطن.

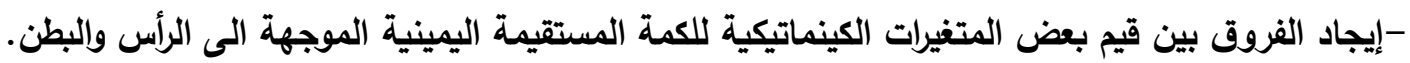
وافترض الباحثان وجود فروق ذات دلالة معنوية بين قيم بعض المتفيرات الكينماتيكية للكمة المستقيمة اليمينية الموجهة الى الرأس والبطن.

واستخدم المنهج الوصفي في البحث، وتكونت عينة البحث من (•) لاعبين من فئة الثباب لمنتخب محافظة نينوى في رياضة الملاكمة،

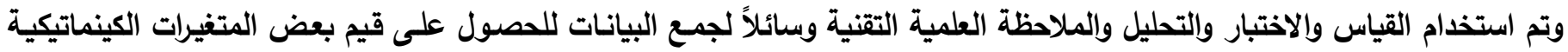
للاعبين، ولتحقيق الملاحظة العلمية التقنية استخدم التصوير الفيديوي.

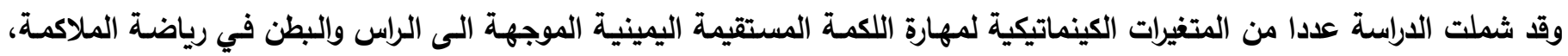
وتم معالجة البيانات احصائيا باستخدام الوسط الحسابي والانحراف المعياري واختبار (T) للعينات المرتبطة. واستنتج الباحثان الى وجود فروق ذات دلالة معنوية بين قيم بعض المتغيرات الكينماتيكية لمهارة اللكمة المستقيمة اليمينية الموجهة الى لى الرأس والبطن. وأوصى الباحثان مجموعة من التوصيات بغية الاستفادة منها في مجال التدريب لتحقيق مستوى أفضل للاعبين.

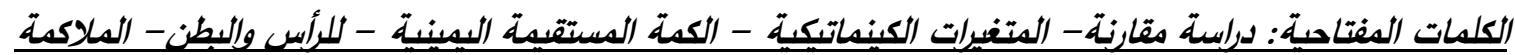

\section{A Comparative study of some Kinematics Variables of the straight Right Punch Directed to the Head \& Abdomen in Boxing} Ahmed Amjad Abdul-Aal

Assist.Prof.Dr. Falah Taha Hammo

\section{$\underline{\text { Abstract }}$}

The research aimed at:

1- Recognizing the values of some of the Kinematics variables of the straight right punch directed to the head.

2- Recognizing the values of some of the Kinematics variables of the straight right punch directed to the Abdomen.

3- $\quad$ Finding the differences among the values of some Kinematics variables of the straight right punch directed to the head and Abdomen.

The study supposed that there were significant differences among the values of some of the Kinematics variables of the straight right punch directed to the head and Abdomen 
The descriptive method was used, the sample included (5) young players of Nineveh team in Boxing. The measurements, analysis and technical scientific observation were used as mean to collect data to obtain some of straight the Kinematics variables values. To achieve the technical scientific observation accurately the videography was used.

The study included a number of Kinematics variables of the direct right punch directed to the head and Abdomen. The data have been processed statistically by using the mean, standard deviation and (T) period test.

The study concluded the following:

There were significant difference between some "Kinematics variables for the straight right punch" directed to the head and abdomen.

The study had recommendations to be utilized in the coaching to achieve the best performance for players.

Keywords: A Comparative Study - Kinematics Variables - Straight Right Punch -Head \& Abdomen - Boxing

$$
\text { - التعريف بالبحث }
$$$$
\text { 1- أمقدمة وأهمية البحث:- البحئ }
$$

بدأت بعض دول العالم اليوم بالتخطيط المبرمج معتمدةً على العلوم التطبيقية في تطوير المستويات الرياضية للألعاب

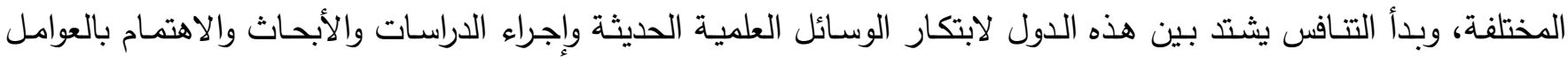
الأساسية التي تدخل في تنفيذ الأداء المهاري لاكتشاف وسائل تدريبية حديثة والاهتمام بالجوانب البدنية الخاصـة باللعبة، فضـلاً

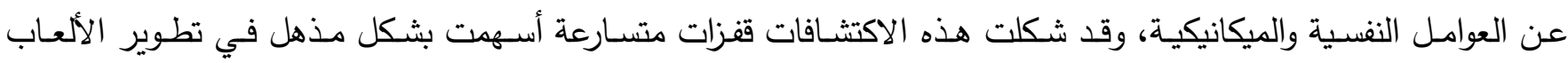
المختلفة، إن هذا التطور اعتمد على العلوم الإنسانية والعمية جميعها، ومنها علم البايوميكانيك الذي يمكن أن يحل واجبات

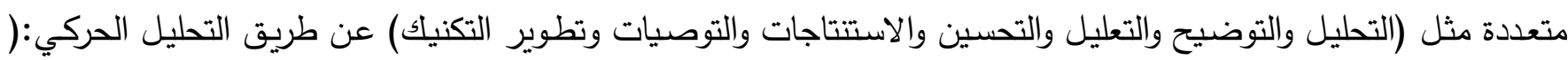
الذي يعد إحدى الطرائق الأساسية لعلم البايوميكانيك إذ يمكن من خلاله تجزئة الحركة إلى أجزائها بحسب نوع التقائ ونسيم المراد، ومن ثم تقرير طبيعـة كل جزء من الحركة من أجل تطبيق الأسس والمبادئ والقوانين الميكانيكية الملائكـة للتكنيك المثالي

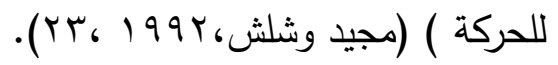
إن اسـتخدام الأجهزة الحديثة والوسـائل العلميـة المتطورة فضـلاً عن التقنيـات المتقدمـة التي تسـهم في تطبيق نتائج البحوث الميدانية والمختبرية، قد سهل مهمة الباحثين والمدربين في اختبار آلية علمية تتسم بالدقة والموضوعية للقياس والتقويم وتوجيه الأداء الفني للمهارات الرياضية الذي يتم بتحليل الحركة تحليلاً دقيقاً عن طريق مقارنة الحقائق بمعايير معينة. وقد شهد المجال الرياضي تطورات علمية من خلال ارتباطه الوثيق ببقية العلوم الأخرى، ومنها علم البايوميكانيك الذي يبحث في دراسة الحركة من حيث مكانها وزمانها والقوى المسببة لها، كما عرف بأنه "دراسة كل من وظيفة وتركيب النظام البيولوجي باستخدام الطرق الميكانيكية" (Bartlett, 2001, 1 (B). ويمكن الاستفادة من علم البايوميكانيك من خـلال تحليل الحركات الرياضية للكثف عن الأخطاء المصاحبة للأداء الفني، "إن الطريقة المثلى في دراسة الحركة وتحليلها ودراسة جميع المتغيرات

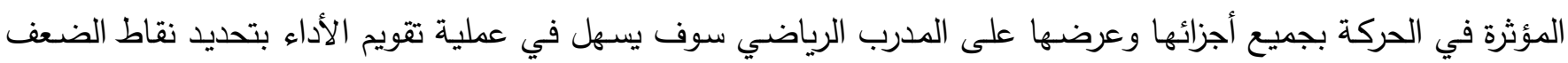

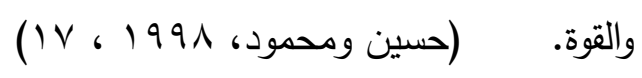

وتعد رياضة الملاكمة رياضة متكاملة من حيث اعتمادها على المتطلبات الاساسية الشاملة لأية لعبة رياضية أخرى، كالأداء المهاري والبدني والخططي والنفسي والعقلي، فهي تتميز بـاختلاف الثـدة والجهد من لحظـة الى أخرى، و تحتوي رياضــة 


\section{دراسة مقارنة لبعض المتفيرات الكينماتيكية للكمة المستقيمة.}

الملاكمة على أنواع عدة من اللكمات منها المستقيمة اليمينية واللكمة الجانبية (الخطافية) واللكمة الصاعدة (القلع)، ولكل من هذه اللكمات اسلوبها الخاص وتأثيرها في منطقة اللكم، وان من بين هذه اللكمات ذات التأثير الأكثر فاعلية والتي شهدت تطورا في مستوى الأداء هي اللكمة المستقيمة الموجهة الى الرأس والبطن، ومن هنا برزت أهمية البحث في اجراء دراسـة تحليلية للكثف عن قيم بعض المتغيرات الكينماتيكية للكمة اليمينية المستقيمة الموجهة إلى الرأس والبطن، واجراء مقارنة بين النوعين

للتعرف على معنوية الغروق، ومن أجل توضيحها ودراستها والاستفادة من نتائج البحث للعاملين في مجال رياضة الملاكمة .

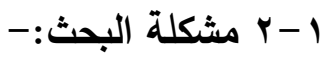

تتحصر مشكلة البحث الأساسية في قلة الدراسـات التي تعنى برياضة الملاكمة من الجانب الميكانيكي للوقوف على دقائق وتفاصيل الحركة وتحليلها من أجل تطوير وتحسين المستوى العام للاعبي الملاكمة في قطرنا، وتحقيق انجازات اكبر، وكذلك للإجابة عن السؤال أي من اللكمتين المستقيمتين اليمينيتين الموجهتين الى الرأس والبطن كانت اكثر فاعلية الى منطقة اللكم من الناحية الميكانيكية، مما حدا بالباحثان الى إجراء دراسة تحليلية مقارنة للكشف عن قيم بعض المتغيرات الكينماتيكية للكمة اليمينية المستقيمة الموجهة إلى الرأس والبطن، والتعرف على مدى الفروق بين تلك القيم من أجل تحسين الإنجاز والارتقاء بمستوى اللاعبين الى الأفضل.

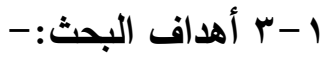

1-1-1 التعرف على قيم بعض المتغيرات الكينماتيكية للكمة المستقيمة اليمينية الموجهة إلى الرأس. 1-r-r-r التعرف على قيم بعض المتغيرات الكينماتيكية للكمة المستقيمة اليمينية الموجهة إلى البطن. 1-r-r إيجاد الفروق بين قيم بعض المتغيرات الكينماتيكية للكمة المستقيمة اليمينية الموجهة الرأس والبطن.

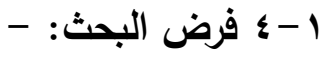

وجود فروق معنوية بين قيم بعض المتغيرات الكينماتيكية للكمة المستقيمة اليمينية الموجهة الى الرأس والبطن.

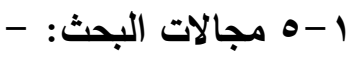
1 - 1- المجال البشري: عينة من لاعبي منتخب محافظة نينوى فئة الثباب في رياضة الملاكمة.

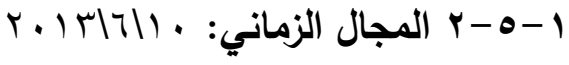
1-ه - المجال المكاني: قاعة الملاكمة التابعة لمنتدى أم الربيعين للشباب والرياضة في محافظة نينوى. 1-7 التعاريف والمصطاحات المستخدمة في البحث: 1-1-1 التحليل الحركي: "هو أحد العلوم الذي يعنى باستخدام الأسس والقوانين التي توضح الشكل الأفضل للأداء الحركي للمهارة، وكذللك بيان الأسباب الميكانيكية للنجاح أو الفشـلفي أداء الحركات وتقدير كون أداء المهارة الحركية التي يؤديها الرياضي متطابقة مع الأداء الأمثل الجيد أم لا على وفق القوانين والأسس الميكانيكية".

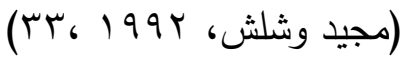

1التطرق الى القوة المسببة للحركة ويطلق عليه علم الوصف الهندسي للحركة. إذ يدخل في دراستها كل من الزمن والإزاحة والزوايا والسرع.

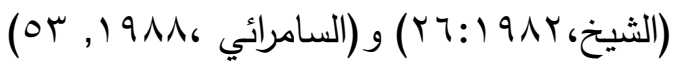


1- إ-ب السرعة الزاوية: هي معدل الانتقال الزاوي للجسم خلال فترة زمنية معينة أو هي القيمة المكانية الزمانية لسرعة

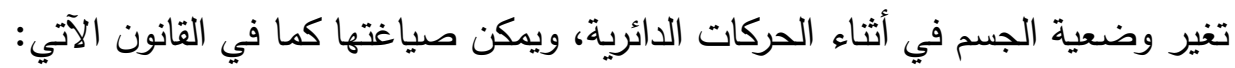

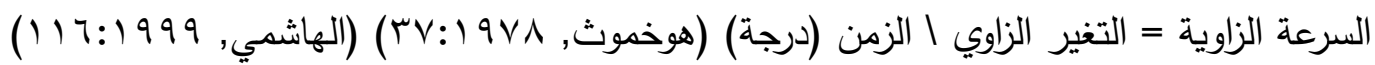

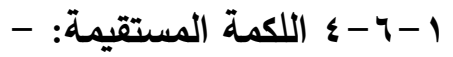

- "وهي اللكمات التي تتطلق نحو هدفها بخط مستقيم وتتنهي باستقامة الذراع بكاملها وتكون موازية للأرض تقريباً “،

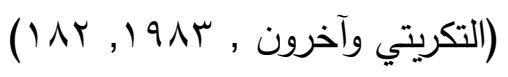

- - التعرف من وجهة النظر الميكانيكية بنظام حركي مركب، يتحدد في تركيبة واحدة.

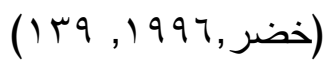

1- 1-ه زمن الاستجابة: هي الفترة الزمنية التي يستغرقها الجهاز العصبي العضلي للاستجابة للمثير.

(تعريف اجرائي)

1-1-7 زمن اللكم: هي الفترة الزمنية المتتغرقة ما بين الثروع بحركة اللكم بعد الاستجابة ولمس القبضة للكيس.

(تعريف اجرائي)

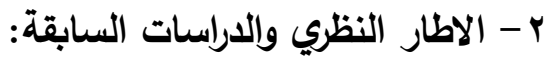

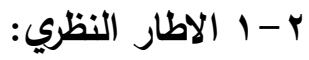

ب - 1- التحليل الحركي وعلاقته بالبايوميكانيك:

ان علم البايوميكانيك يُعنى بتحليل الحركات وتوضيح وتحسين فن الأداء الرياضي (التكنيك) ويبحث قوانين وشـروط

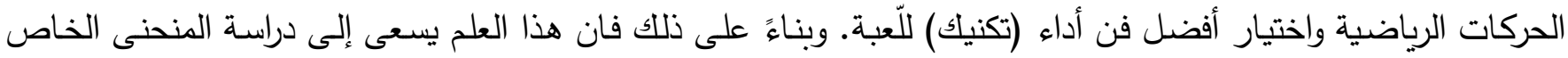

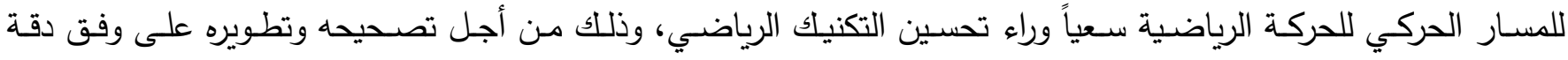

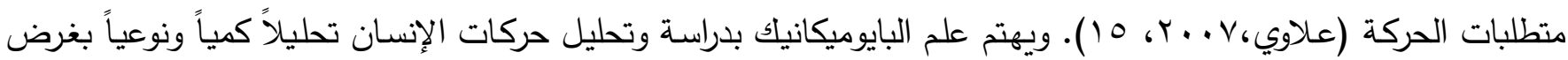

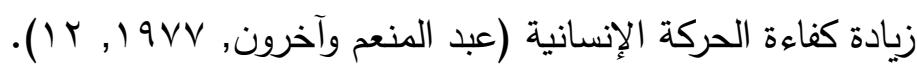

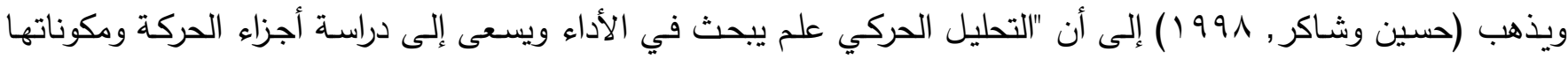

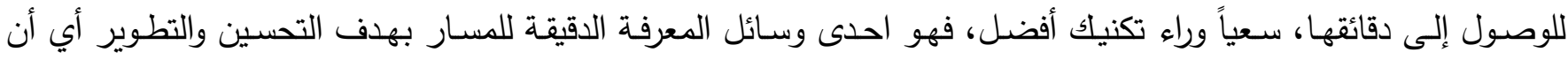

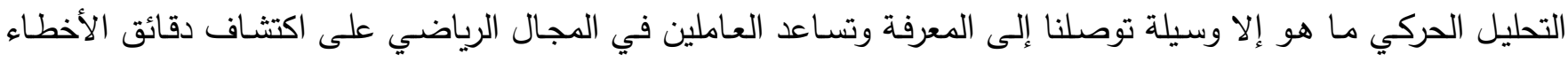

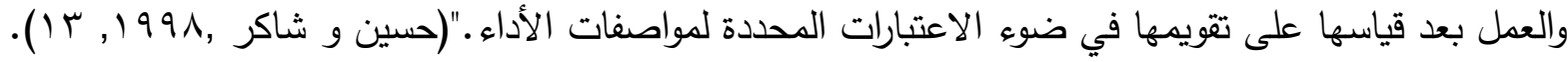

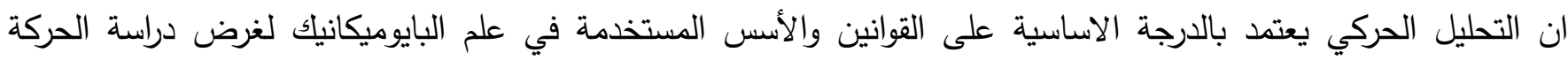

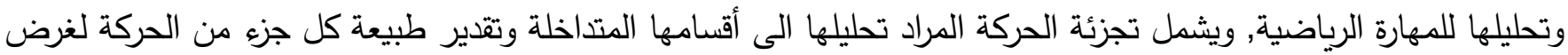

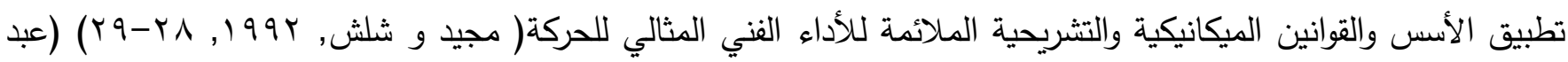

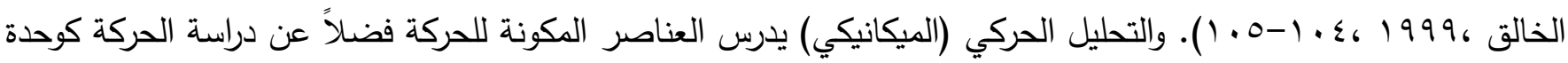

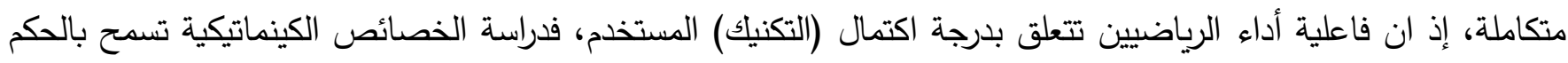
على مستوى إتقان الأداء (حسين ومحمود, 991 1, 01). والتحليل في المجال الرياضي هو أحساء الحد العلوم التي ترتكز على علوم 


\section{دراسة هقارنة لبعض المتفيرات الكينماتيكية للكمة المتقيمة}

أخرى، مثل الرياضيات والإحصاء والفيزياء والميكانيكا الحيوية والعلوم الأخرى المرتبطة بالحركة لذلك لا يمكن إجراء التحليل

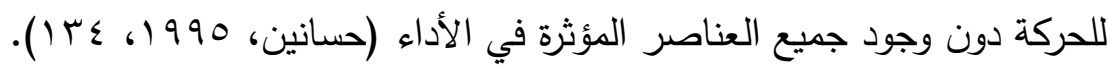

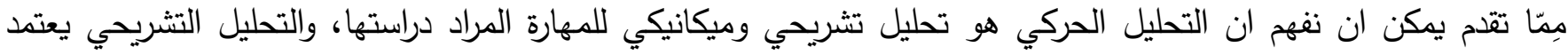

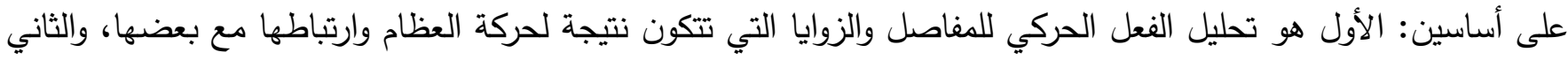
هو تحليل القوة العضلية التي تنتجها العضلات بسبب الانقباضات الدختلفة الثدة.

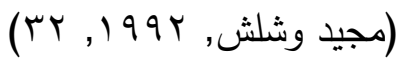

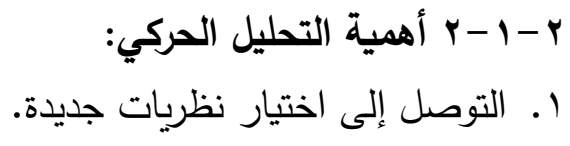

r. r. اختيار الحركات الصحيحة والملائمة للظروف المحيطة بالإنجاز .

r. المعرفة التامة بالمهارات المراد تعليمها والتدريب عليها من الناحية العلمية مما يتطلب الإلمام بالمبادئ الأساسية للتثريح والفسيولوجيا والميكانيكا والعلوم الأخرى.

ع. تحليل الحركات الرياضية وتوضيحها.

ه. تشخيص الحركات وأجزائها ومقارنة هذه الأجزاء المحللة بإنجاز حركي آخر .

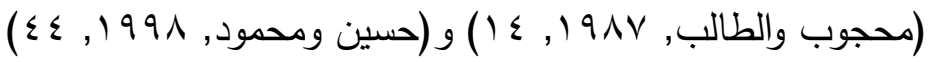

r-1 - ب التحليل الحركي باستخدام التصوير الفيديوي: ظهر هذا النوع من التحليل مع بداية الحاجة إلى دراسة الخصائص (التكنيكية) المميزة للمهارات، ومحاولة التعرف على التى التئي مميزات وعيوب الطرائق المختلفة لأداء المهارة، بهدف صياغة الخطوات التعليمية والتدريبات الأساسية لهذه المهارات بشكل علمي يضمن تحقيق مستويات أعلى للأداء.

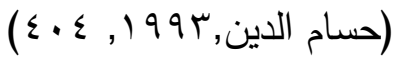

ويُعَد التصوير الفيديوي من أفضل الطرائق التي تخدم التحليل البايوكينماتيكي لأنها تسمح بالتحسس من بعد ولا تتداخل أصلاً

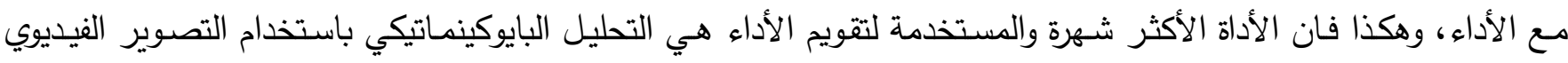

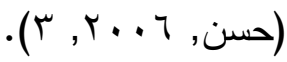

يجب ان يستخدم (تكنيك) التحليل الفيديوي الأساسي بشكل مكثف من قبل المدربين في تحليل المهارات الفردية للاعبين عند

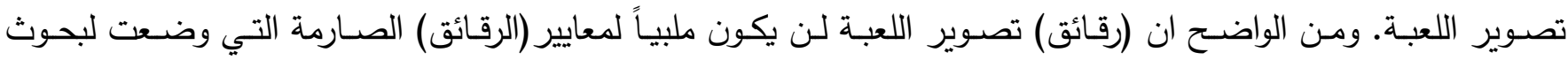

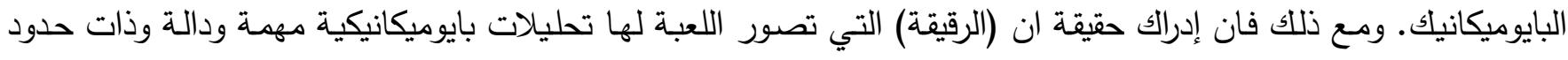

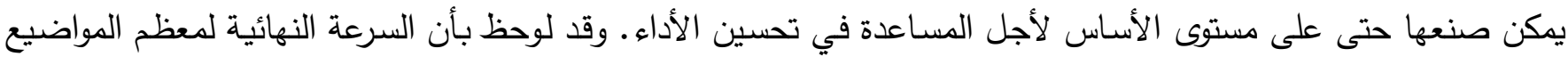

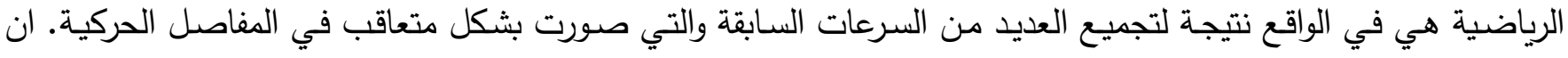

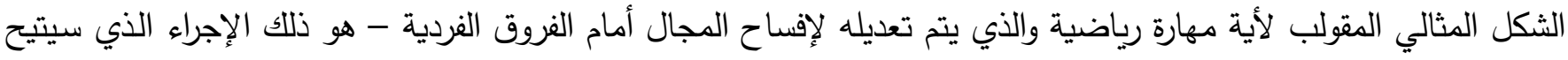
لنا جمع هذه السرعات الفردية مع بعضها بشكل أكثر فعالية لإعطاء نتيجة مثالية.

(Northrip and others 1979, 18) 
ץ-1 - - المهارات الاساسية بالملاكمة:

$$
\begin{aligned}
& \text { 1-وقفة الاستعداد. } \\
& \text { r- זركات القدمين. } \\
& \text { r- اللكمات. } \\
& \text { ع - اللكم المضاد. } \\
& \text { ه- الطرق الدفاعية. }
\end{aligned}
$$

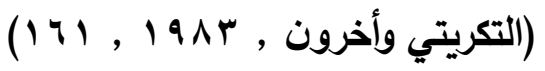

ب- ب- أنواع اللكمات:

أولا: لكمات مستقيمة:

$$
\text { 1- إكمات مستقيمة يسارية (للوجه وللجسم وللبطن). }
$$$$
\text { r- لكمات مستقيمة يمينية (للوجه وللجسم وللبطن). }
$$

ثانيا: لكمات جانبية (خطافية): -

1- لكمات جانبية يسارية (للوجه وللجسم وللبطن).

$$
\text { r- اكمات جانبية يمينة (للوجه وللجسم وللبطن). }
$$

ثالثا: لكمات صاعدة (القلع): -

1- لكمات صاعدة يسارية (للبطن وللجسم وللحنك وللوجه).

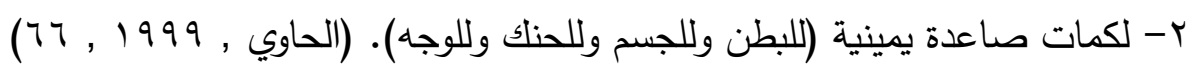

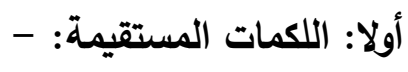

تعد اللكمات المستقيمة أولى اللكمات استخداما، وقد عرفت تعريفات كثيرة منها: - (نظام حركي مركب يتحدد في تركيبة

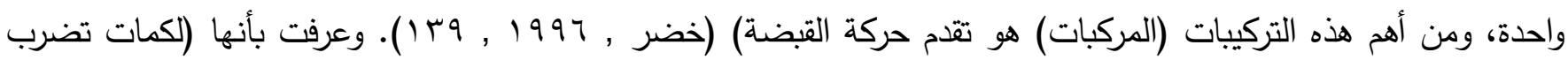
أو توجه للأمام بشكل مستقيم على مستوى النظر وتصيب الوجه أو الجسم أو البطن من الأمام وتتميز بدقة الإصابة وبشدتها

$$
\text { وبسرعة وصولها إلى الهدف إذا أديت بإتقان). }
$$

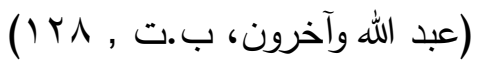

$$
\text { اللكمات المستقيمة اليسارية للرأس: - }
$$

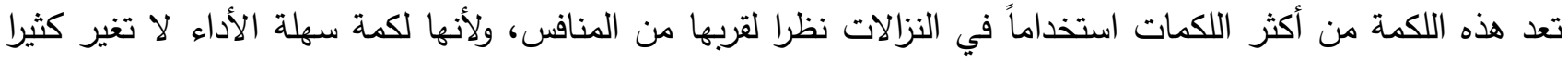

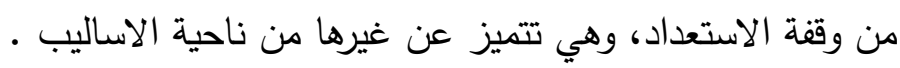

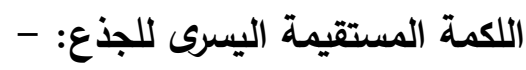

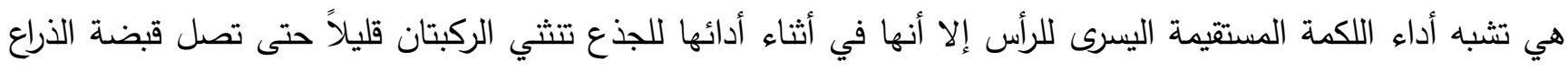

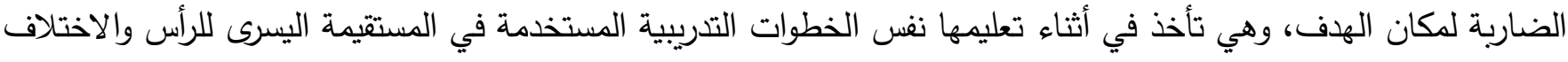

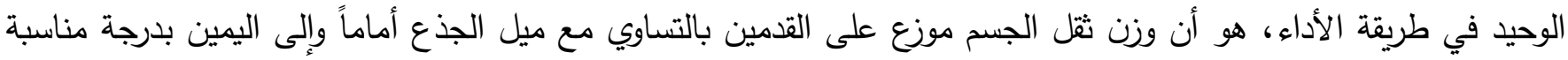
لتفادي لكمات المنافس المقابل. ( $1 \leqslant V, 1997$, (خضر) 


\section{دراسة مقارنة لبعض المتفيرات الكينماتيكية للكمة المستقيمة..........}

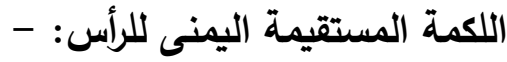

تعد هذه اللكمة من اللكمات القوية المهمة ذات التأثير الفعال في مستوى سير اللكم، لما تتميز به من المدى الحركي الكبير

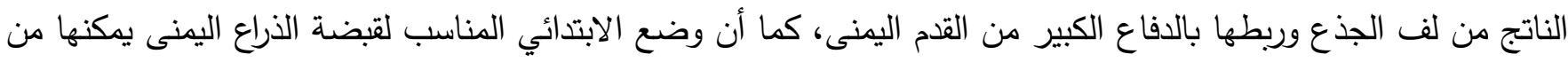
دقة وقوة التسديد.

(التكريتي واخرون , 1919. (191)

اللكمة المستقيمة (اليمين للجذع): طريقة الأداء وخطوات التعليم كما في اللكمة اليمنى للرأس، وقد شهدت فروقا قليلة في الأداء وهي زيادة في ثني الركبتين وميل الجذع الى الامام ولليسار والمحافظة على مبدأ التغطية والاتزان كما في وقفة الاستعداد.

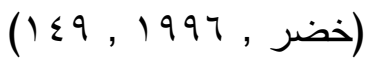

(وتعد هذه اللكمة أكثر استخداما من المستقيمة اليمنى الموجهة إلى الرأس بسبب انخفاض وضعها، وتؤدى هذه اللكمة بعد

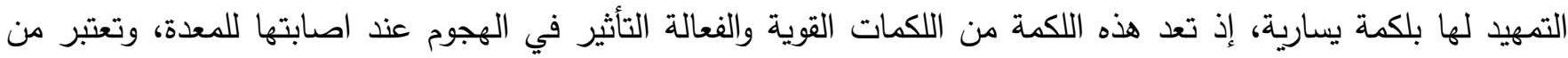

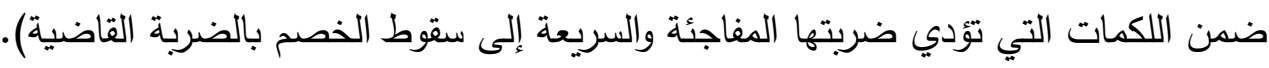

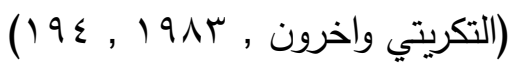

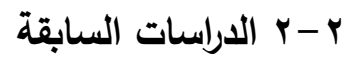
دراسة زيبار حسين طاهر (11 +rم) (دراسة تحليلية لبعض المتغيرات البايوكينماتيكية لمهارة اللكمة المستقيمة وعلاقتها بدقة

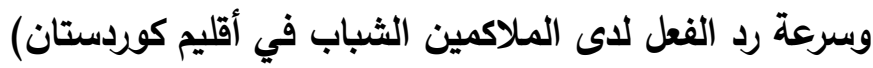

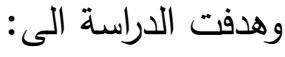

1- التعرف على أهم قيم بعض المتغيرات البايوكينماتيكية لمهارة اللكمة المستقيمة.

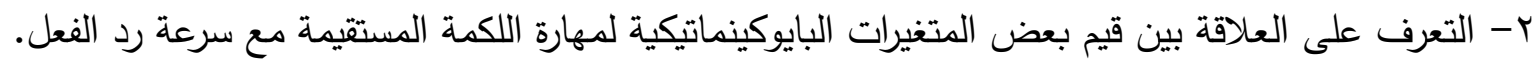

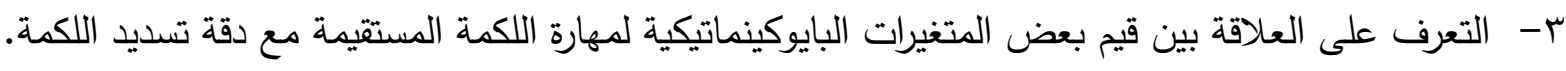

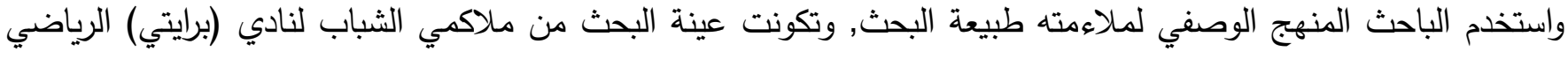

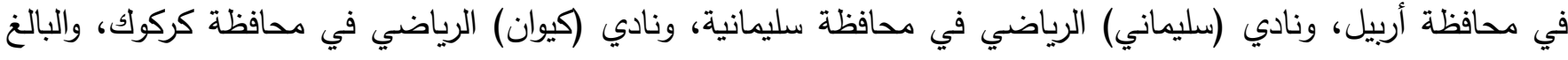

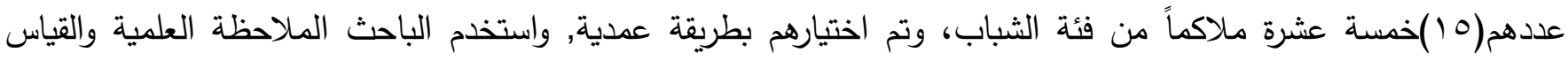
والتحليل والدقابلات الثخصية والاستبيان كوسائل لجمع البيانات للحصول على قيم بعض المتغيرات البايوكينماتيكية لعينة البحث ولتحديد اهم الاختبارات لقياس دقة تسديد اللكمة . 
واستنتج الباحث: -

1- وجود علاقة معنوية بين بعض المتغيرات البايوكينماتيكية وزمن رد الفعل في مراحل (لحظة الاستجابة و لحظة ضرب الكيس) حيث كان هناك علاقة معنوية بين كل من (زاوية مفصل المرفق الايسر وزاوية مفصل الكتف اليسار وزاوية مفصل الورك دكائ وزاوية مفصل الركبة اليمين وزاوية مفصل الركبة اليسار ) وبين زمن رد الفعل.

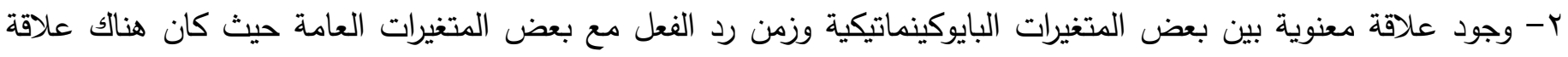
معنوية بين كل من (الازاحة الافقية لليد، والسرعة الافقية لليد، السرعة الزاوية للمفصل المرفق، والازاحة الافقية للورك، والسيركة

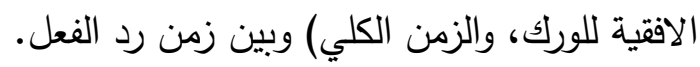

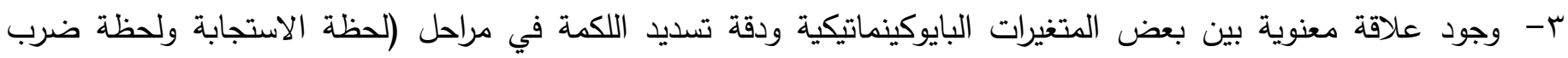
الكيس)، حيث كان هناك علاقة معنوية بين كل من (زاوية مفصل المرفق الايسر ، وزاوية مفصل الكتف اليسار ، وزاوية مفصل

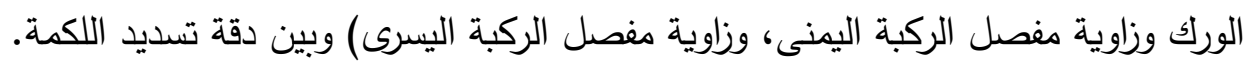

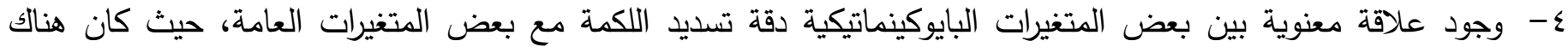

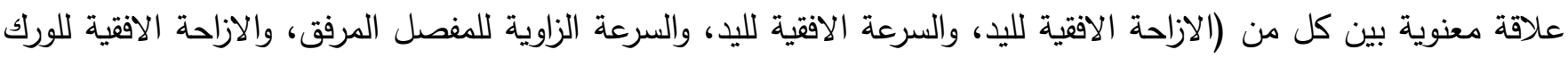
والسرعة الافقية للورك، والزمن الكلي) وبين دقة تسديد اللكمة.

\section{مناقثة الاراسة السابقة}

- - اختلفت دراسة (زيبار حسين طاهر) عن الدراسة الحالية في نوع اللكمة المستقيمة الموجهة، اذ استخدم الباحث اللكمة اليسارية

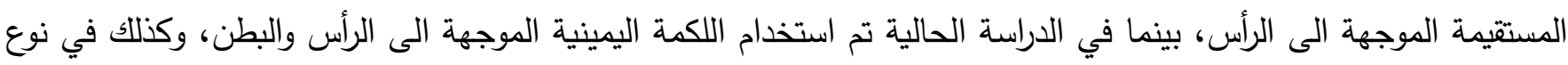

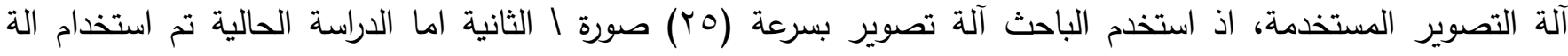

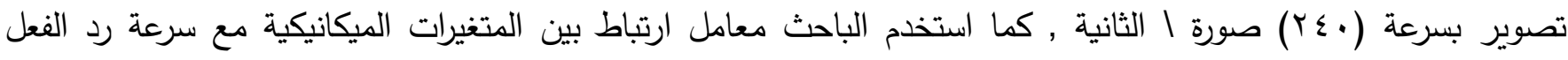
والدقة، بينما في الدراسة الحالية تم استخدام الدقارنات لبعض المتغيرات الكينماتيكية بين كلتا اللكتين اليمينية الموجهة الى لى الرأس والبطن. - - متثابهت هذه الدراسة مع الدراسة الحالية بنوع العينة من فئة الثباب. 


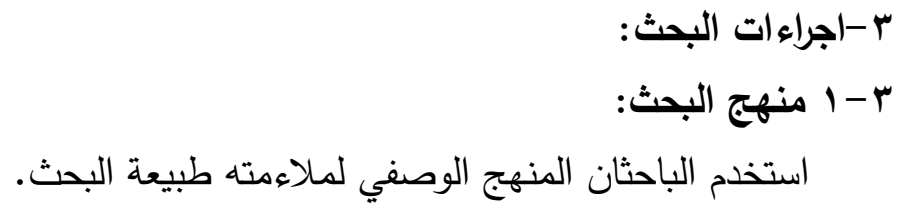

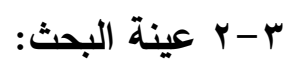

تم اختيار عينة البحث بالطريقة العمدية من لاعبي منتخب محافظة نينوى فئة الشباب في رياضة الملاكمة مكونة من خمسة لاعبين، والحاصلين على مراكز متقدمة على مستوى القطر، وتم اجراء التجانس لعينة البحث بالاعتماد على معامل الاختلاف لكل من (العمر والعمر التدريبي والطول والكتلة)، الجدول (1) يبين مواصفات عينة البحث.

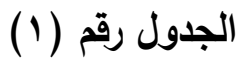

يبين المعالم الاحصائية لبعض القياسات الجسمية والعمر لعينة البحث

\begin{tabular}{|c|c|c|c|c|c|}
\hline الكتلة الكتل & الطول & العمر التدريبي & العمر الزمني & 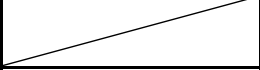 & ت \\
\hline 52 & 172 & 2.5 & 17 & علي ناصر احمد & 1 \\
\hline 59 & 170 & 2 & 16 & نوار خميس حمح & r \\
\hline 58 & 170 & 1 & 19 & احمد عبد الله & $r$ \\
\hline 73 & 175 & 2 & 16 & خالد وليد جمال & $\varepsilon$ \\
\hline 64 & 167 & 2 & 19 & سمير جاسم تحمد & 0 \\
\hline 61.20 & 170.80 & 1.90 & 17.40 & س- & \\
\hline 7.85 & 2.95 & 0.55 & 1.52 & $\varepsilon$ & \\
\hline$\% 12.83$ & $\% 1.73$ & $\% 28.83$ & $\% 8.72$ & معامل الاختلاف & \\
\hline
\end{tabular}

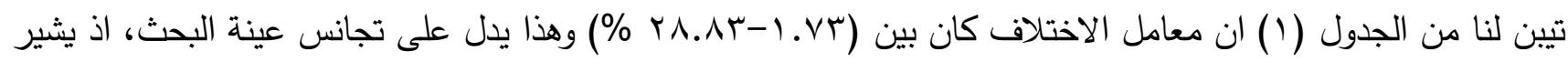

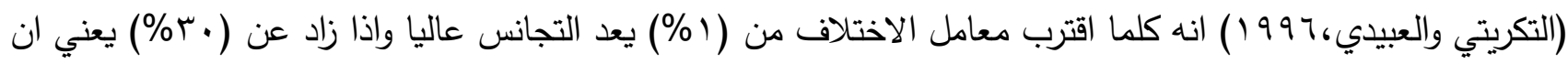
العينة غير متجانسة.

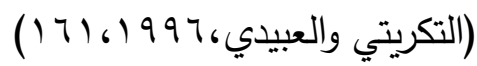

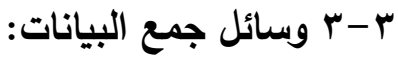

استخدم الباحثان الملاحظة العلمية التقنية والقياس والتحليل والاستبيان وسائل لجمع البيانات للحصول على قيم بعض

المتغيرات الكينماتيكية والقياسات الجسمية للملاكمين.

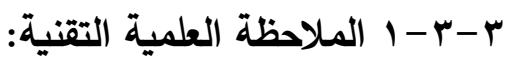

لتحقيق الملاحظة العلمية التقنية استخدم الباحثان التصوير الفيديوي ، وذلك باستخدام آلتي تصوير فيديوية، الأولى (باتى

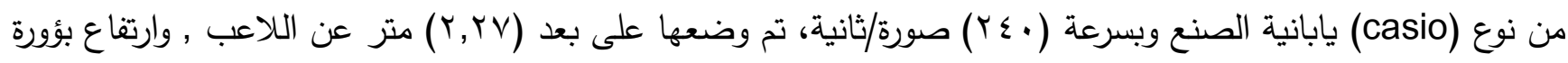

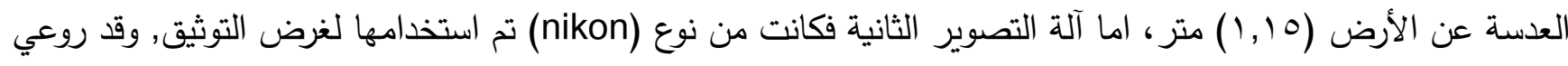

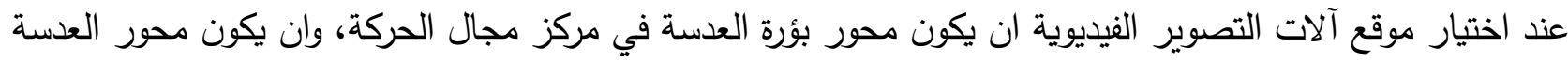

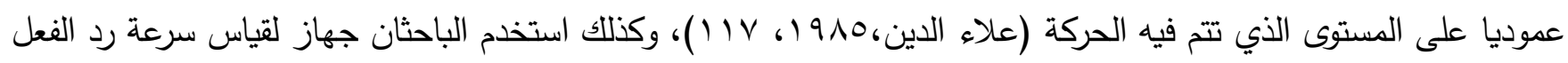




\section{دراسة مقارنة لبعض المتفيرات الكينماتيكية للكمة المستقيمة.}

عدد (Y) المكون من (ستاند) ويعلوه اضاءة بلون أحمر، وفيه جرس لزيادة عدد المثيرات وضع الأول امام اللاعب والآخر أمام

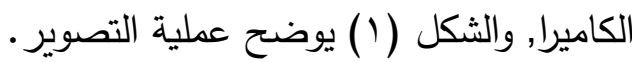

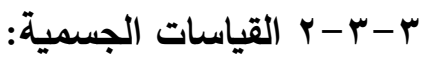

r-r-r-r-r-r-r-r الطول (سم): تم قياس الطول الكلي للجسم باستخدام جهاز (الرستاميتر).

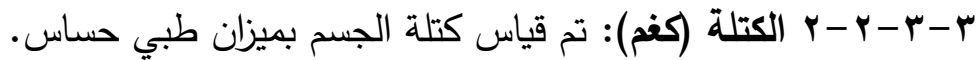

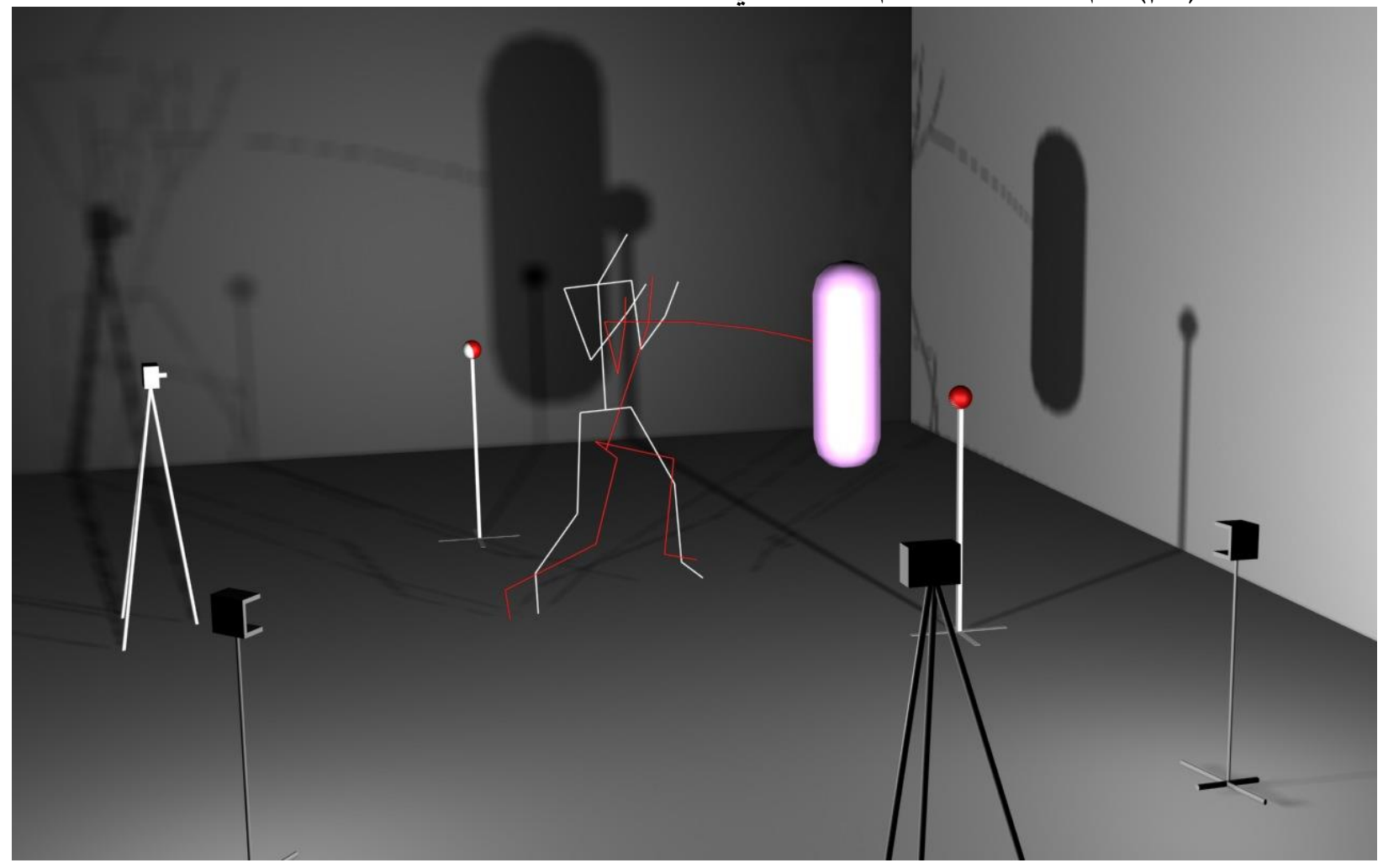

الثكل( ( ) يوضح طريقة وضع الاجهزة والادوات المستخدمة في عملية التصوير

ץ- ؟ الاجهزة والادوات المستخدمة في البحث: -

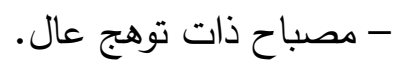
- آلة تصوير من نوع (Nikon). - ميزان طبي حساس. - حاسوب محمول نوع (ASUS). - شريط قياس.

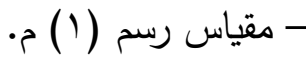

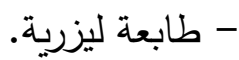
ب- ب طريقة استخلاص البيانات: بعد ان تم تسجيل محاولات الملاكمين بوساطة آلة التصوير الفيديوي من نوع (Casio)وتحويلها الى الحاسوب وثم تقطيع الفيديو الى صور او فريمات بوساطة برنامج (adobe Photoshop cc) واخذ الصور المراد العمل بها الى برنامج 


\section{دراسة مقارنة لبعض المتفيرات الكينماتيكية للكمة المستقيمة..........}

وذللك لتحديد احداثيات الحاسبة النقطية (AutoCAD) (Excel) (ترتيب البيانات الخام وتحويلها بمعاملات التحويل الى بيانات رقمية ذات دلالة يمكن فهمها.

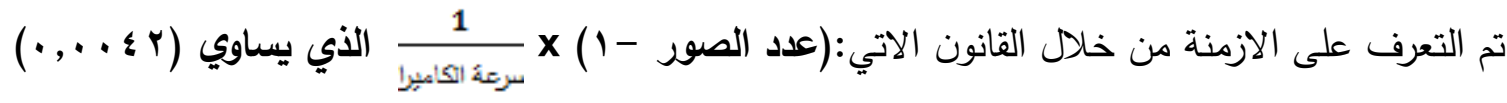

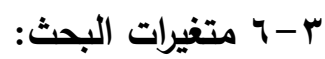

1- زوايا مفاصل وأجزاء الجسم الاتية للوضع التحضيري والرئيس:

$$
\text { - - زاوية مفصل - زاوية الذراع مع الكاحل. - }
$$

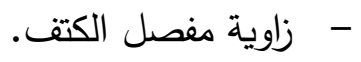

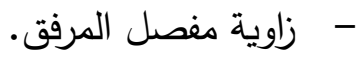

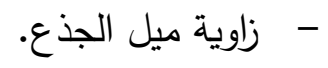

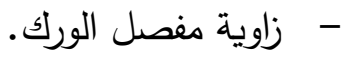

ץ- الازاحات الافقية والعمودية والمحصلة للكمة اليمينية الموجهة الى الرأس والبطن.

ب- ك- زمن الاستجابة للمثير.

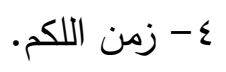

0- السرعة الافقية والعمودية والمحصلة للكمة اليمينية الموجهة الى الرأس والبطن.

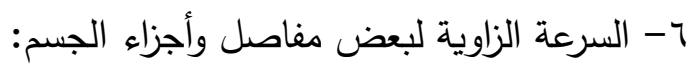

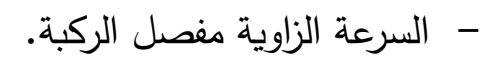

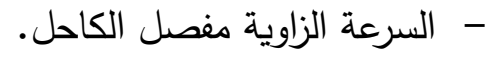
- - - - السرعة الزاوية للذراع مع الكيس.

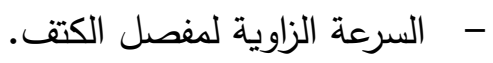
- - - السرعة الزاوية لمفصل المرفق.

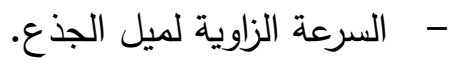

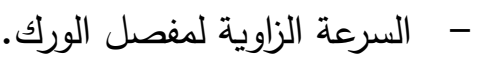

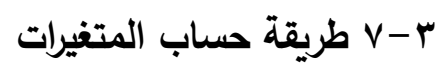

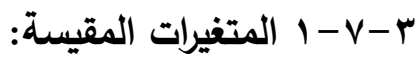

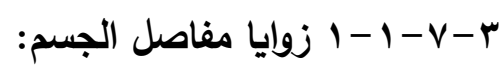

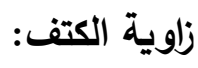

تم قياسها من خلال الزاوية المحصورة بين عظم العضد من جهة والخط النازل من مفصل الكتف الى مفصل الورك من جهة

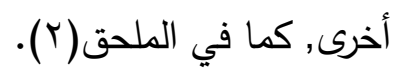

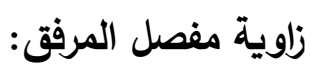

تم قياسها من خلال الزاوية المحصورة بين الخط الواصل بين نقطة مفصل الكتف الى نقطة مفصل المرفق من جهة والخط

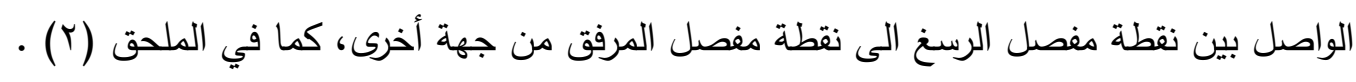

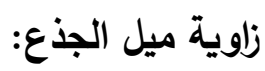

تم قياسها من خلال الزاوية المحصورة بين الخط النازل من نقطة منتصف الكتفين الى منتصف الوركين من جهة وخط الأفق

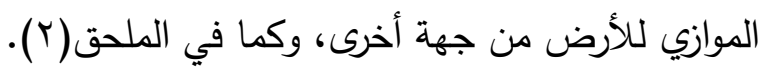


زاوية مفصل الورك:

تم قياسها من خلال الزاوية المحصورة بين الخط الواصل من نقطة الكتف إلى نقطة مفصل الورك من جهة، والخط الواصل من

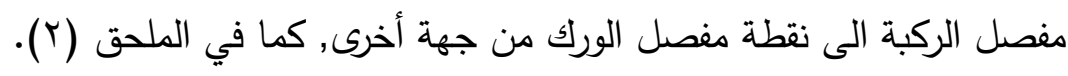

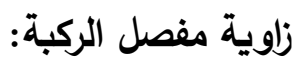

تم قياسها من خلال الزاوية المحصورة بين الخط الواصل من نقطة مفصل الورك الى نقطة مفصل الركبة من جهة، ومفصل

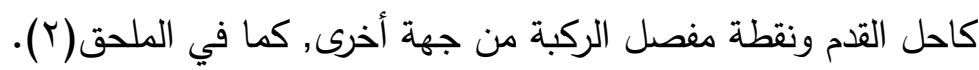

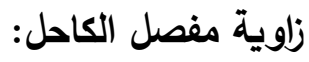

تم قياسها من خلال الزاوية المحصورة بين الخط الواصل من نقطة مفصل الركبة الى مفصل كاحل القدم من جهة، ونقطة مقدمة القدم من جهة أخرى.

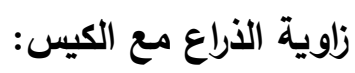

تم قياسها من خلال الزاوية المحصورة بين الخط الوهمي لامتداد الذراع لحظه لمس القفاز للكيس من جهة والخط العمودي لامتداد الكيس من جهة أخرى. : r r- r- r r الازاحات

الإزاحة الأفقية للكمة:

تم قياسها من خلال المسافة المقطوعة بين نقطة مقدمة الكف في وضع الاستعداد الى نقطة مقدمة الكف لحظة لمس الكيس، كما في الملحق(r). العمودية للكمة: العان

تم قياسها من خلال المسافة المقطوعة بين نقطة مقدمة الكف في وضع الاستعداد الى نقطة مقدمة الكف لحظة لمس الكيس،

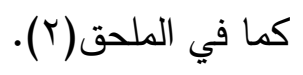
محصلة الازاحة للكمة: تم حسابها من خلال تطبيق نظرية فيثاغورس.

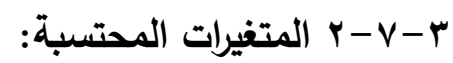

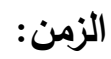

تم استخراج الزمن عن طريق معرفة زمن الصورة الواحدة كما يأتي:

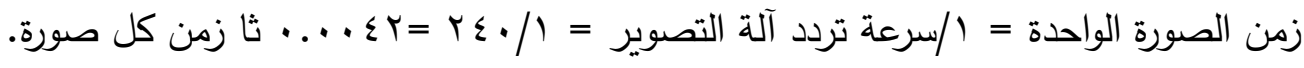

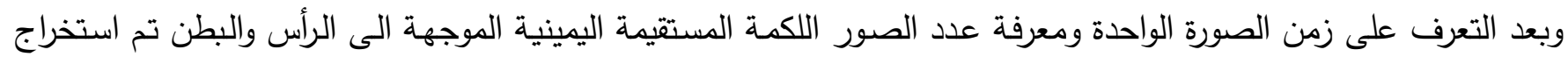

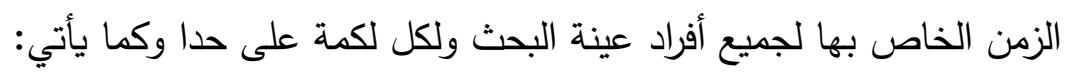
(عدد صور اللكمة-1) × (1ا زمن الصورة) = زمن اللكمة. 


\section{السرعة الافقية وإلعمودية وإلمحلة: \\ تم استخدام القانون الآتي لحساب السرعة الإفقية والعمودية: -

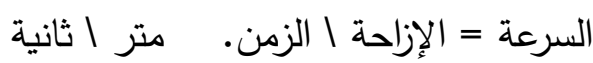 اما السرعة المحصلة تم حسابها من خلال قانون فيثاغورس الإسله

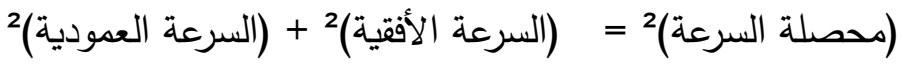

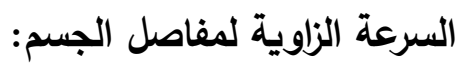

وذلك عن طريق حساب الفرق الزاوي ما بين زوايا مفاصل الجسم في وضع الاستعداد وزوايا مفاصل الجسم عند وضع اللكم مقسوما على زمن، كما في القانون الآتي:

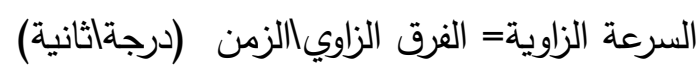

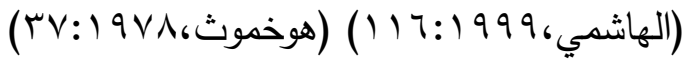

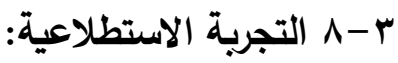

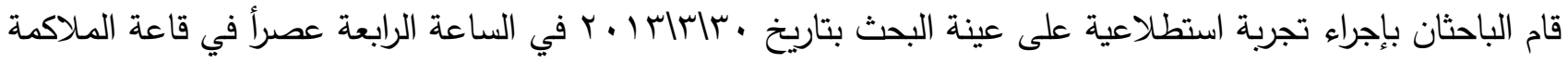

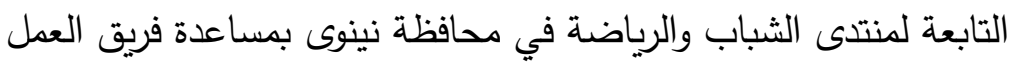

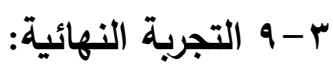

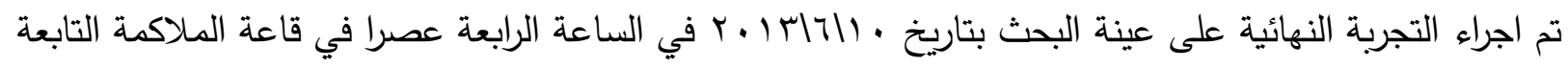

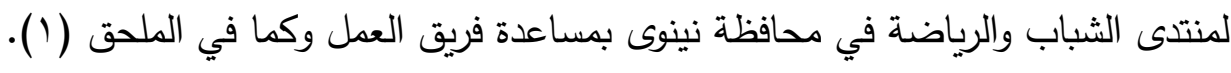

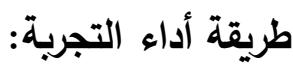

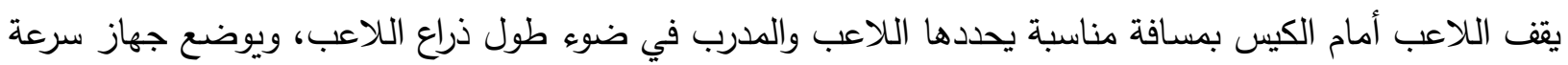

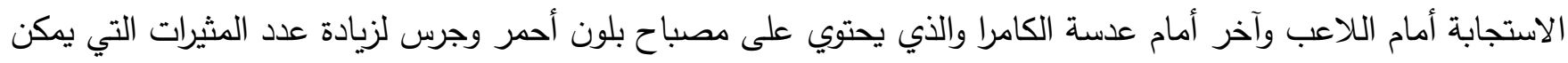

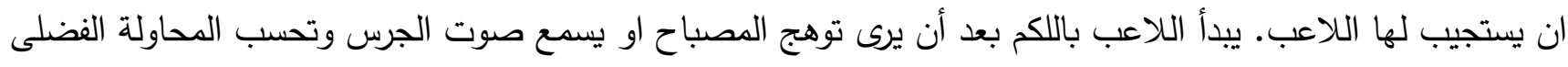

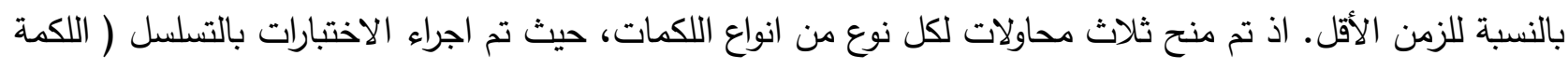

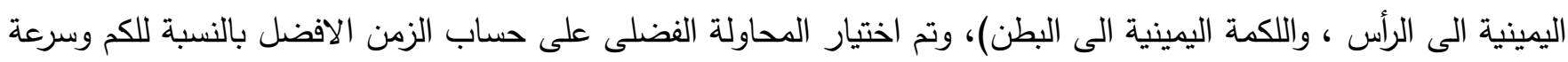

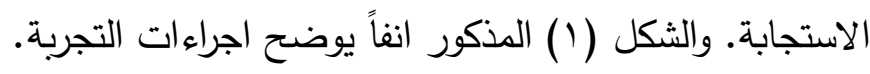

$$
\begin{aligned}
& \text { r- ب-1 المعالجات الاحصائية: } \\
& \text { تم استخدام الوسائل الإحصائية الآتية: }
\end{aligned}
$$

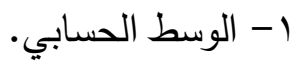

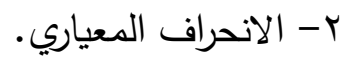

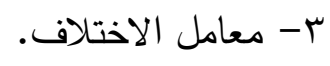

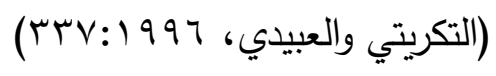

ع - اختبار T-Test اللعينات المرتبطة.

وتم معاملة البيانات احصائيا باستخدام الحاسوب الالي ضمن حزم البيانات (Excel) و (SPSS). 
ع - عروض ومناقثة النتائج

ـ - اعرض ومناقثة نتائج متغيرات الزوايا

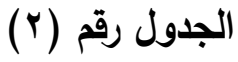

يبين المعالم الاحصائية لمتغيرات زوايا مفاصل واجزاء الجسم للكمة اليمينية الى الراس والبطن (الوضح الرئيس) (درجة)

\begin{tabular}{|c|c|c|c|c|c|}
\hline \multirow{2}{*}{ قالمحسو (ت) } & \multicolumn{2}{|c|}{ اللكمة الى البطن } & \multicolumn{2}{|c|}{ اللكمة الى الراس } & \multirow{2}{*}{ المتغيرات } \\
\hline & $\varepsilon \pm$ & سَ & $\varepsilon \pm$ & سَن سن & \\
\hline 1.129 & 12.59 & 114 & 12.48 & 120.2 & زاوية مفصل الكتف اليمنى \\
\hline 0,563 & 6.06 & 22.2 & 10.66 & 24.8 & زاوية مفصل الكتف اليسرى \\
\hline 0,749 & 2.86 & 174.8 & 0.89 & 175.6 & زاوية مفصل المرفق الايمن \\
\hline 1.090 & 20.71 & 49 & 14.05 & 61 & زاوية مفصل المرفق الايسر \\
\hline 2.187 & 10.33 & 71.8 & 6.04 & 79 & زاوية الجذع \\
\hline $4.027 *$ & 15.01 & 112.8 & 12.75 & 155 & زاوية مفصل الركبة اليمنى \\
\hline $3.894 *$ & 13.97 & 117.4 & 10.07 & 148 & زاوية مفصل الركبة اليسرى \\
\hline 1.879 & 19.65 & 81.4 & 4.32 & 97.2 & زاوية مفصل الكاحل الايمن \\
\hline 1.532 & 8.70 & 98.8 & 10.18 & 110.2 & زاوية مفصل الكاحل الايسر \\
\hline $3.574 *$ & 22.53 & 149.8 & 10.89 & 173.8 & زاوية مفصل الورك اليمنى \\
\hline $3.942 \%$ & 17.85 & 121.6 & 11.46 & 149.4 & زاوية مفصل الورك اليسرى \\
\hline $4.622 *$ & 9.31 & 90.8 & 10.28 & 80.2 & زاوية الذراع مع الكيس \\
\hline
\end{tabular}

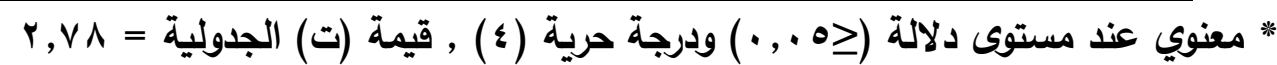

تبين لنا من الجدول (r) الذي يمثل المعالم الاحصائية لمتغيرات زوايا مفاصل واجزاء الجسم للكمة اليمينية الموجهة الى الراس

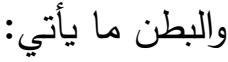

ظهور فروق ذات دلالة معنوية في قيم متغيرات الزوايا الآتية: -

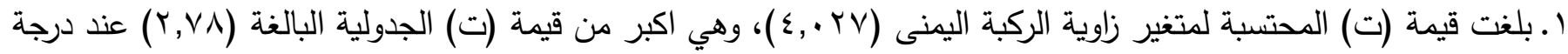

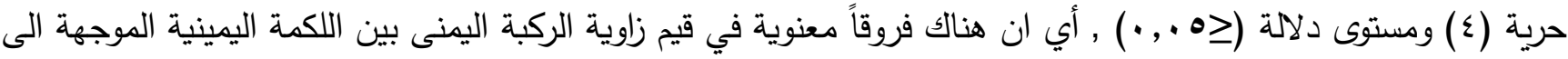

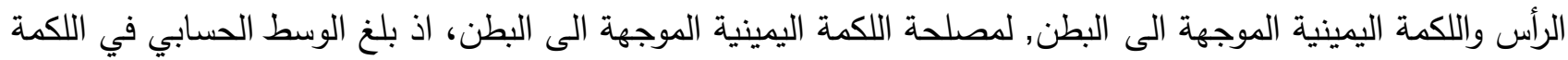
اليمينية الموجهة الى البطن (1, I, (I)، بينما كان الوسط الحسابي في اسلوب اللكمة اليمينية الموجهة الى الرأس (100) ,

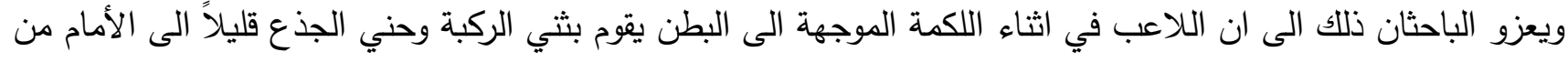
اجل خفض مركز تثل الجسم وايصال اللكمة الى البطن ولتفادي لكمات الخصم في اثناء النزال، وهذا يتقق مع ما ذكره

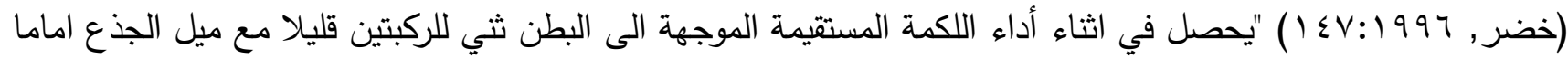


بدرجة مناسبة حتى تصل قبضة الذراع الضاربة الى مكان الهذف, ولتفادي لكمات المنافس المقابل", فيودي ذلك الى صغر

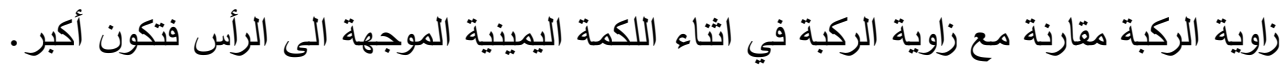

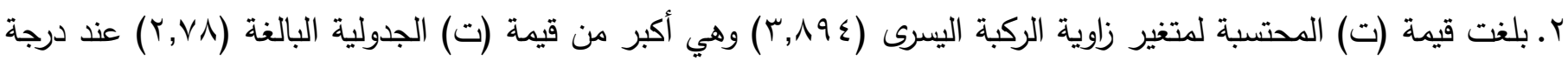

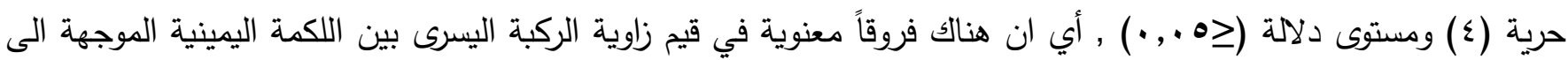

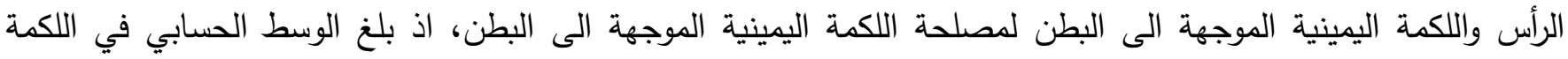

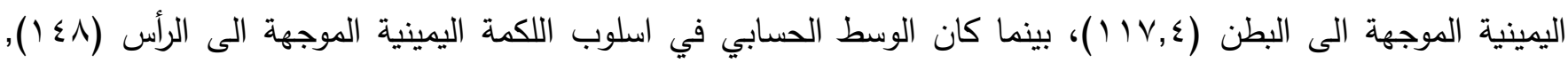

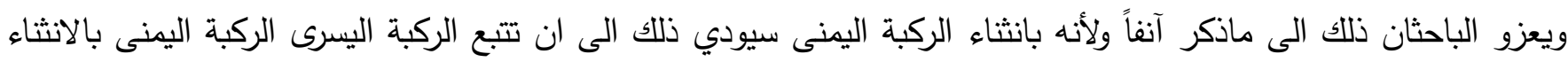

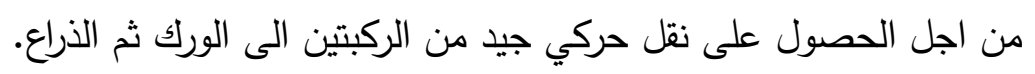

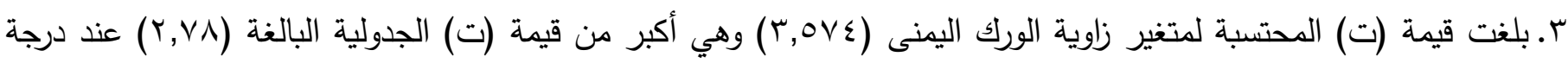

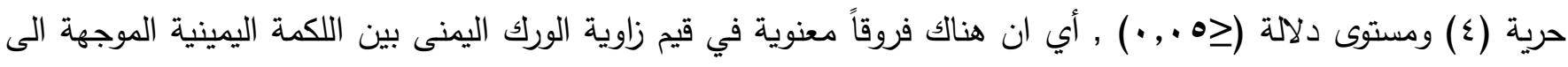

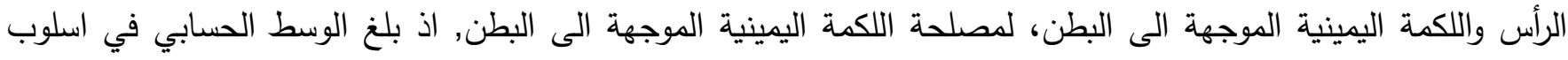

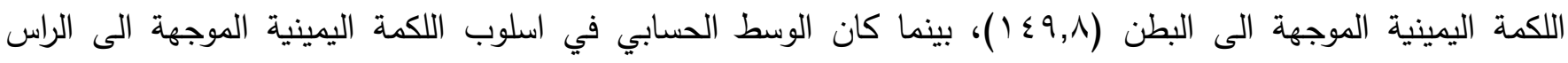

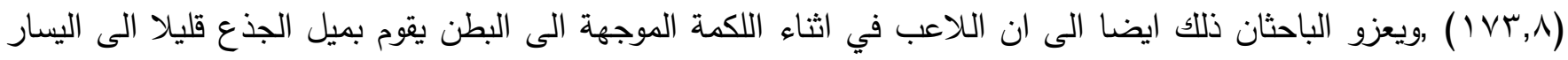

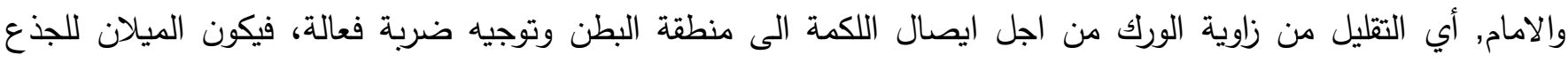

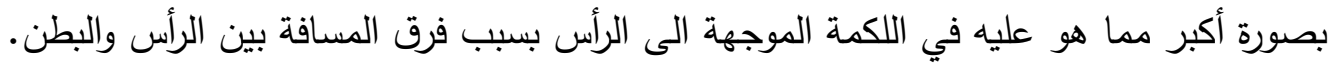

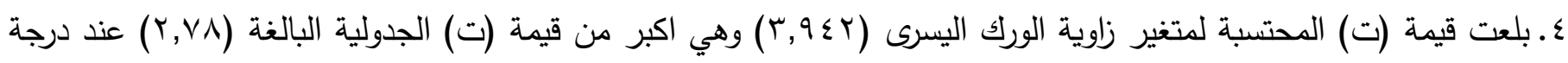

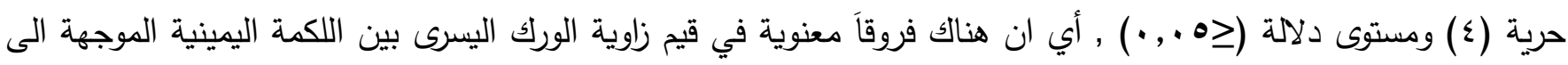

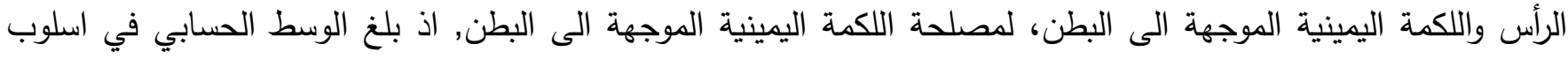

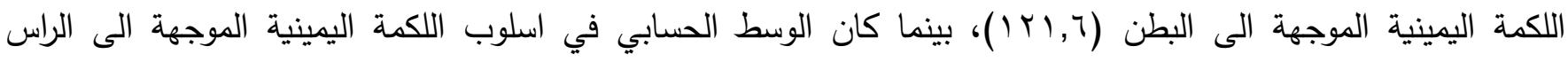

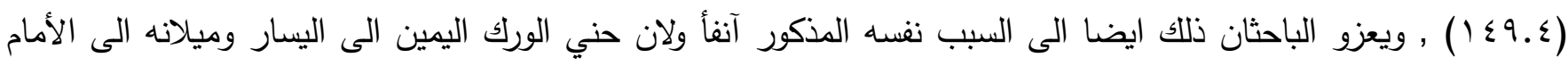

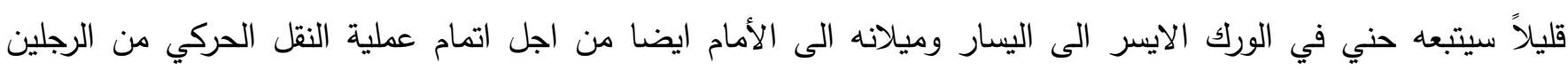

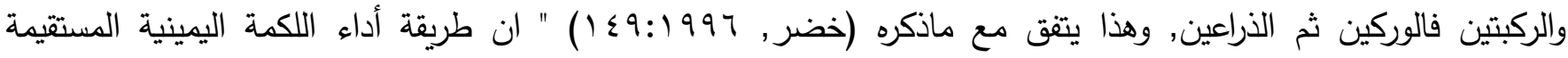

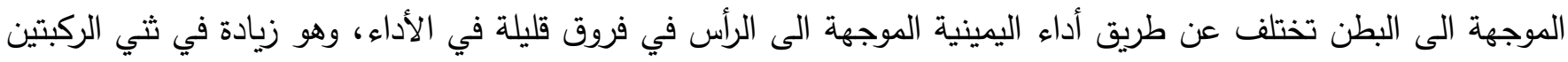

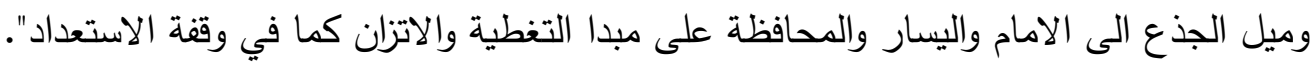

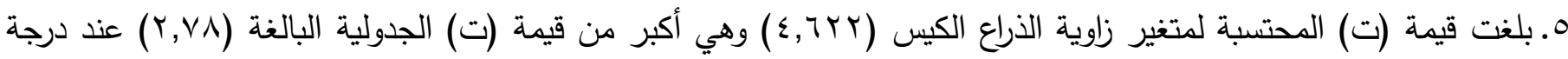

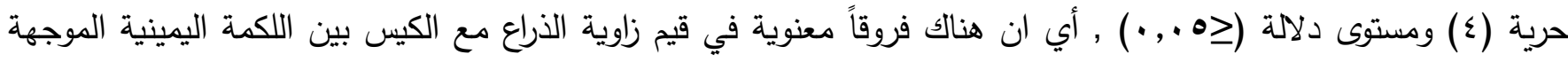

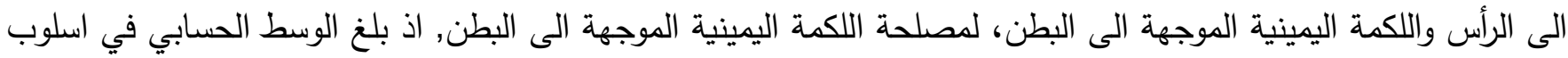

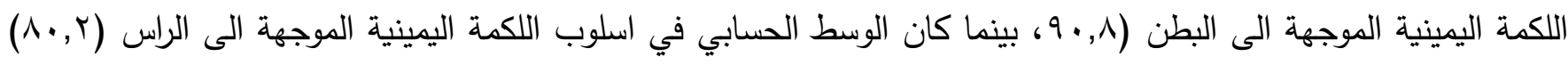

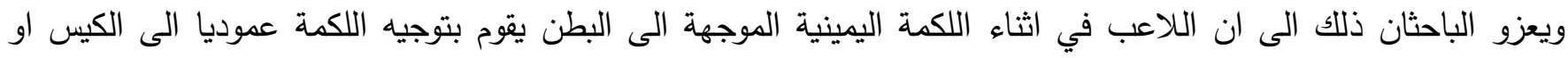

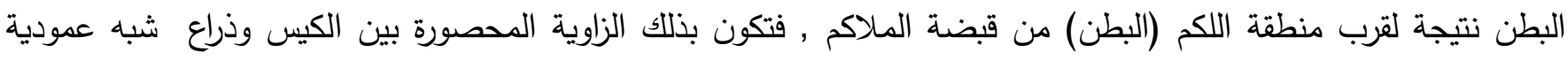

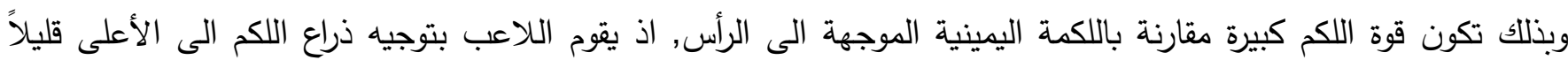


نتيجة لبعد منطقة الرأس عن قبضة اللكم، فتكون بذلك الزاوية المحصورة بين الكيس وذراع اللكم أقل مما هي عليه في اللكمة

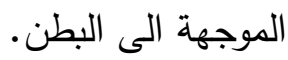

ع - r عرض ومناقثة نتائج متغيرات (السرعة الزاوية)

الجدول رقم (r)

يبين المعالم الاحصائية لمتغيرات السرعة الزاوية لمفاصل واجزاء الجسم للكمة اليمينية الموجهة الى الرأس والبطن (درجة|نا)

\begin{tabular}{|c|c|c|c|c|c|}
\hline \multirow{2}{*}{ قيمة (ت) } & \multicolumn{2}{|c|}{ اللكمة الى البطن } & \multicolumn{2}{|c|}{ اللكمة الى الراس } & \multirow{2}{*}{ المتغيرات } \\
\hline & $\varepsilon \pm$ & سَ س س & $\varepsilon \pm$ & سَ & \\
\hline 0,302 & 219.34 & 735.78 & 209.93 & 753.03 & مفصل الكتف اليمنى \\
\hline 2.011 & 86.94 & 150.05 & 60.47 & 92.79 & مفصل الكتف اليسرى \\
\hline 0,676 & 168.41 & 895.00 & 239.89 & 957.51 & مفصل المرفق الايمن \\
\hline 0,478 & 171.86 & 154.80 & 112.59 & 182.29 & مفصل المرفق الايسر \\
\hline$* 2.948$ & 77.25 & 161.19 & 42.89 & 105.86 & زاوية الجذع \\
\hline$* 3.715$ & 123.47 & 280.27 & 80.64 & 76.93 & مفصل الركبة اليمنى \\
\hline$* 4.222$ & 95.39 & 255.44 & 55.51 & 100.46 & مفصل الركبة اليسرى \\
\hline 2.560 & 85.20 & 268.84 & 63.56 & 118.83 & مفصل الكاحل الايمن \\
\hline 0,619 & 88.91 & 76.23 & 64.19 & 107.93 & مفصل الكاحل الايسر \\
\hline$* 2.962$ & 134.97 & 296.52 & 83.21 & 101.70 & مفصل الورك اليمنى \\
\hline$* 4.002$ & 116.22 & 264.55 & 87.34 & 92.27 & مفصل الورك اليسرى \\
\hline
\end{tabular}

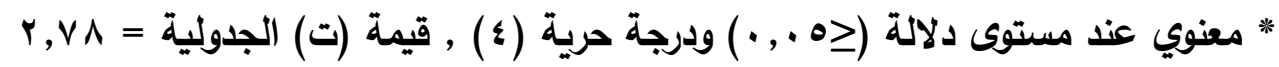

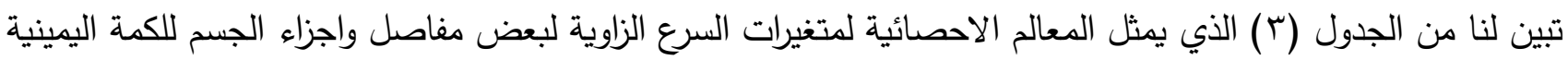
الموجهة الى الرأس والبطن ما يأتي: ظهور فروق ذات دلالة معنوية في قيم متغيرات السرع الزاوية الآتية: -

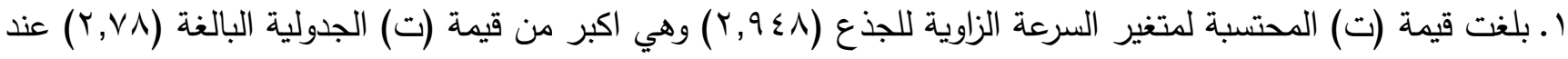

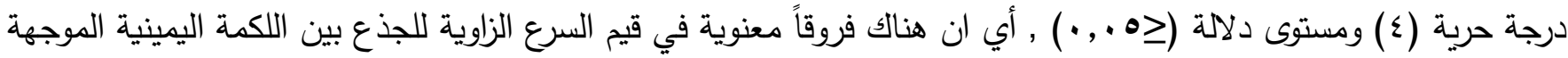

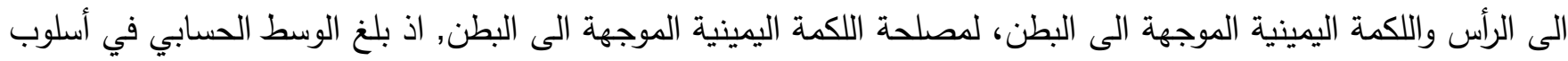

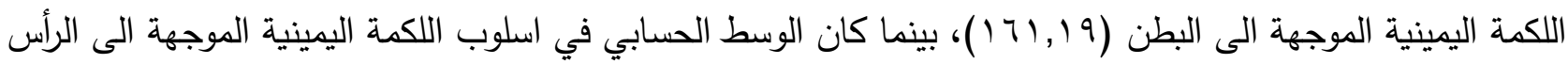

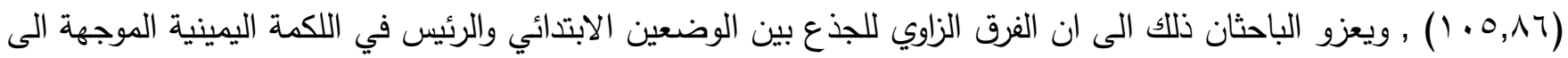

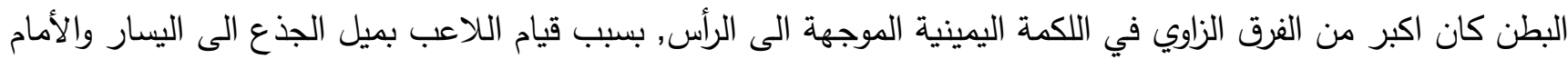


قليلا في اللكمة الموجهة الى البطن من أجل توجيه اللكمة الى منطقة البطن , وكذلك عند النزال من أجل مراوغة اللاعب

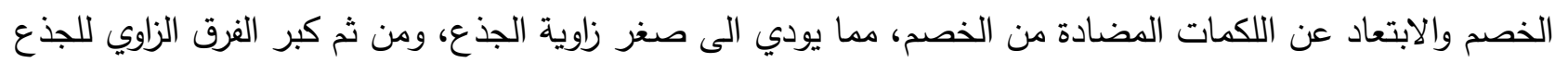
وبالنتيجة كبر السرعة الزاوية للجذع.

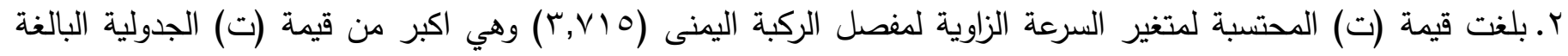
(Y,YA)

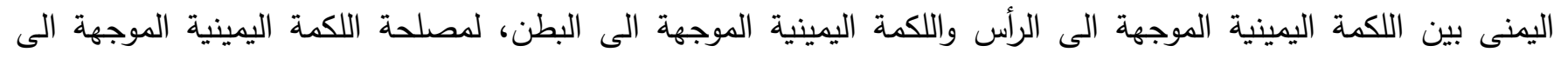

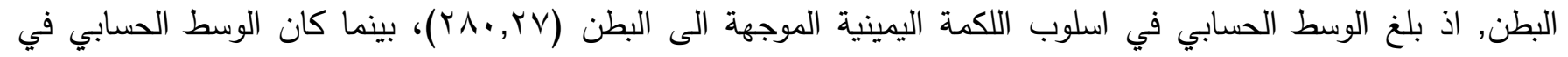
اسلوب اللكمة اليمينية الموجهة الى الراس (T/,9T) , ويعزو الباحثان ذللك الى ان الفرق الزاوي لمفصل الركبة اليمنى بين

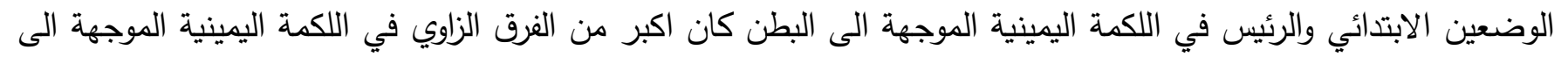

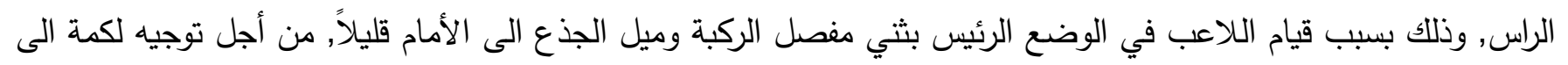

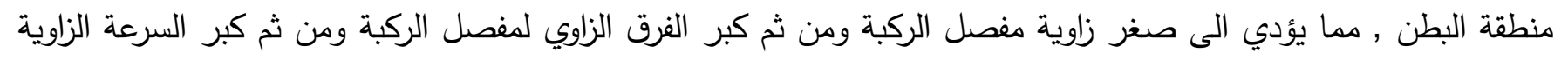
لبف لمفل الركبة. r.بلغت قيمة (ت) المحتسبة لمتغير السرعة الزاوية لمفصل الركبة اليسرى (rrاr,؛) وهي اكبر من قيمة (ت) الجدولية البالغة (Y,Y^)

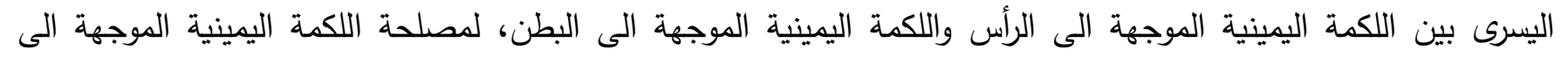

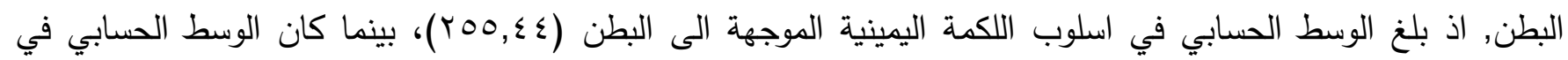

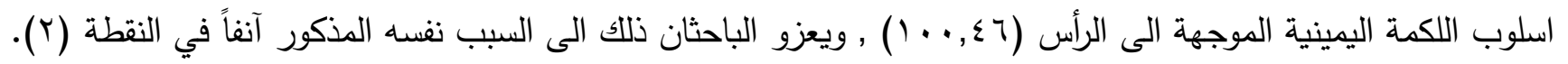

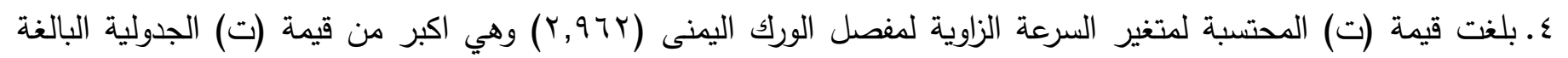
(Y,YA)

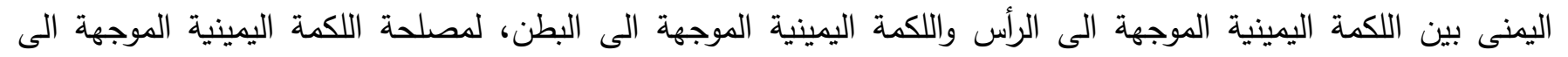

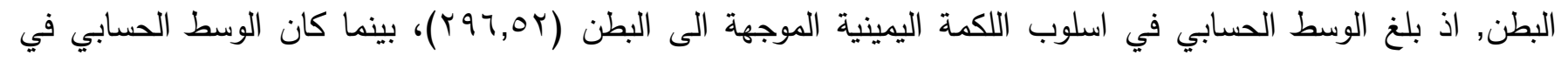

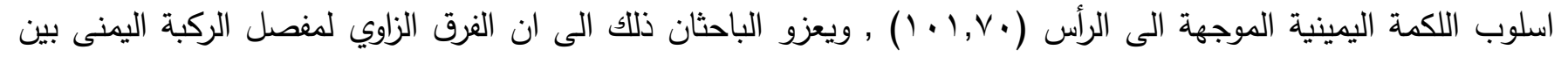

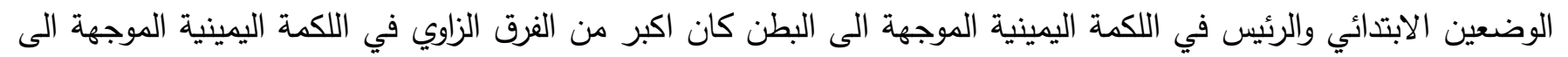

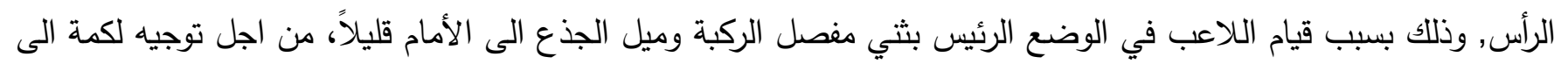

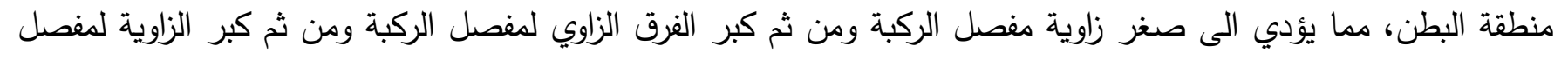
الركبة.

0. بلغت قيمة (ت) المحتسبة لمتغير السرعة الزاوية لمفصل الورك اليسرى (ץ ..,_) وهي اكبر من قيمة (ت) الجدولية البالغة (Y,YA)

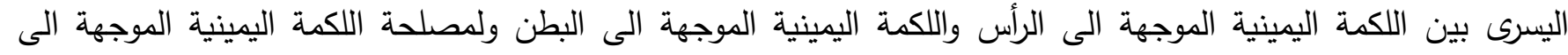

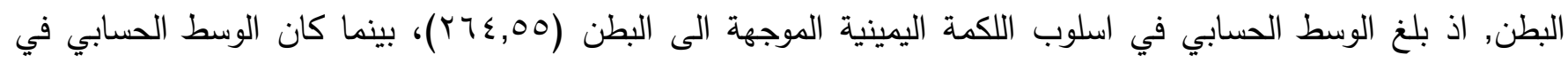

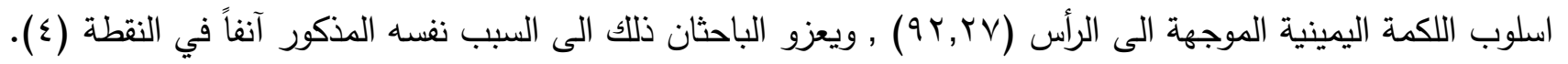


ع - ب عرض ومناقثة نتائج متغيرات الزمن

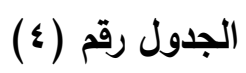

يبين المعالم الاحصائية لمتغيرات الزمن للكمة اليمينية الموجهة الى الرأس والبطن (ثأ)

\begin{tabular}{|c|c|c|c|c|c|}
\hline \multirow{2}{*}{ قالمحتسبة (ت) } & \multicolumn{2}{|c|}{ اللكمة الى البطن } & \multicolumn{2}{|c|}{ اللكمة الى الراس } & \multirow[t]{2}{*}{ المتغيرات } \\
\hline & $\varepsilon \pm$ & سَ & $\varepsilon \pm$ & سَ & \\
\hline 0.07 & 0.091 & 0.332 &.$\wedge 90$. & 0.331 & زمن الاستجابة \\
\hline 0.334 & 0.020 & 0.136 & $.1 \wedge 0$. & 0. & زمن اللكم \\
\hline
\end{tabular}

تبين لنا من الجدول (؛) الذين يمثل المعالم الاحصائية لمتغيرات الزمن للكمة اليمينية الموجهة الى الراس والبطن عدم ظهور

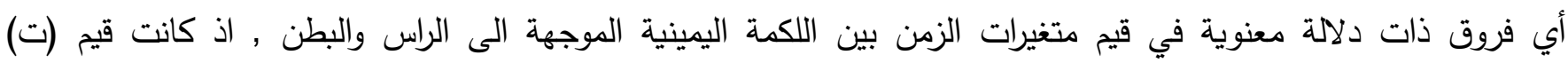

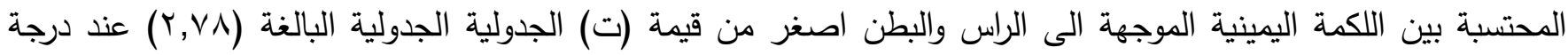

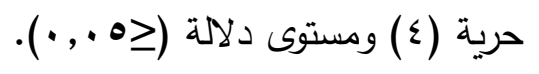

؟ - ؛ عرض ومناقثة نتائج متغيرات الازاحة

الجدول رقم (0) - (0)

يبين المعالم الاحصائية لمتغيرات الازاحة للكمة اليمينية الى الراس والبطن (م)

\begin{tabular}{|c|c|c|c|c|c|}
\hline \multirow{2}{*}{ قالمحتسبة (ت) } & \multicolumn{2}{|c|}{ اللكمة الى البطن } & \multicolumn{2}{|c|}{ اللكمة الى الراس } & \multirow[t]{2}{*}{ المتغيرات } \\
\hline & $\varepsilon \pm$ & سَن & $\varepsilon \pm$ & سَن & \\
\hline 0.241 & 0.035 & 0.699 & 0.075 & 0.688 & الازاحة الافقية \\
\hline $3.287 *$ & 0.060 & 0.230 & 0.065 & 0.089 & الازاحة العمودية \\
\hline 0.892 & 0.039 & 0.739 & 0.082 & 0.696 & محصلة الازاحة \\
\hline
\end{tabular}

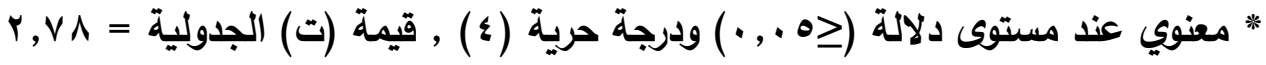

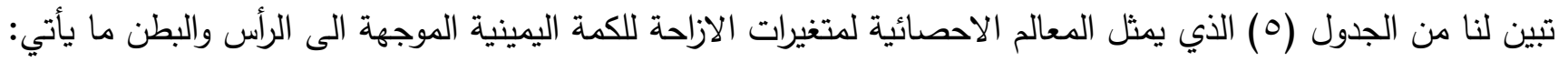

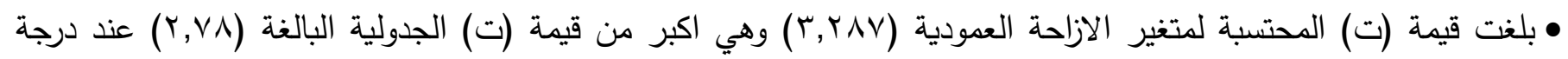

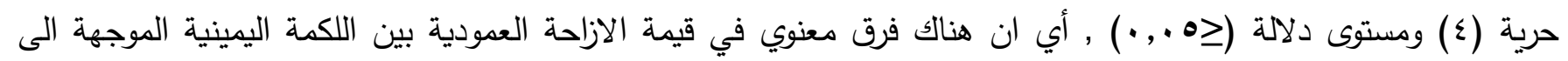

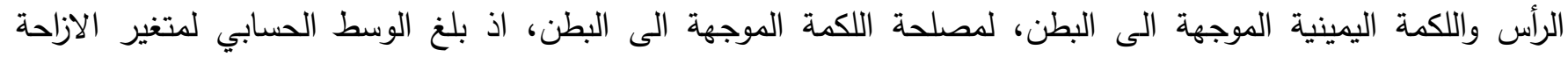

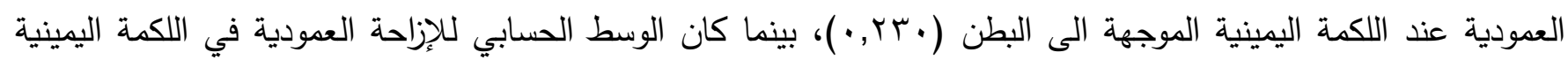

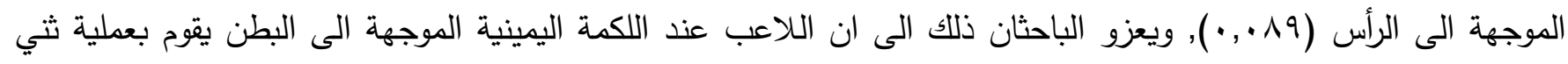

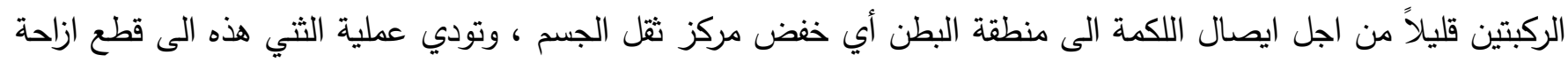
عمودية لمستوى القبضة اكثر مما هي عليه عند اللكمة اليمينية الموجهة الى الرأس. 
ـ - -ه عرض ومناقشة نتائج متغيرات السرعة

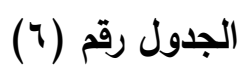

يبين المعالم الاحصائية لمتغيرات السرعة للكمة اليمينية الى الرأس والبطن (ماثا)

\begin{tabular}{|c|c|c|c|c|c|}
\hline \multirow{2}{*}{ قالمحتسبة (ت) } & \multicolumn{2}{|c|}{ اللكمة الى البطن } & \multicolumn{2}{|c|}{ اللكمة الى الراس } & \multirow[t]{2}{*}{ المتغيرات } \\
\hline & $\varepsilon \pm$ & سَ س & $\varepsilon \pm$ & سَنَ & \\
\hline 0.003 & 0.898 & 5.236 & 0.695 & 5.238 & السرعة الافقية \\
\hline $2.866 *$ & 0.448 & 1.701 & 0.474 & 0.684 & السرعة العمودية \\
\hline 0.409 & 0.906 & 5.529 & 0.734 & 5.298 & محصلة السرعة \\
\hline
\end{tabular}

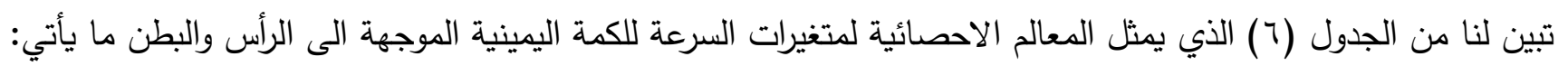

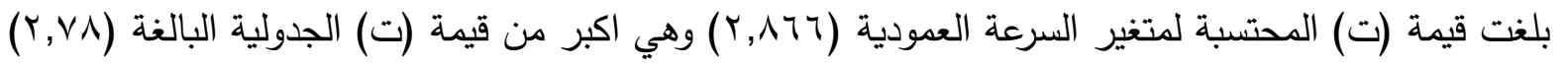

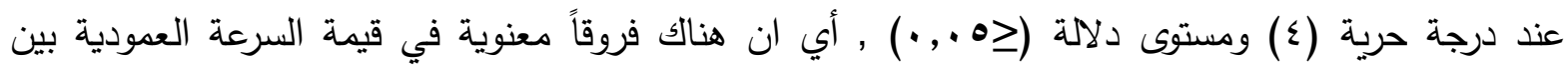

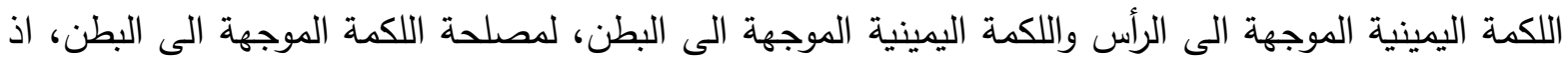

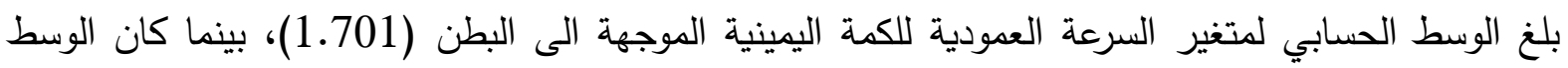

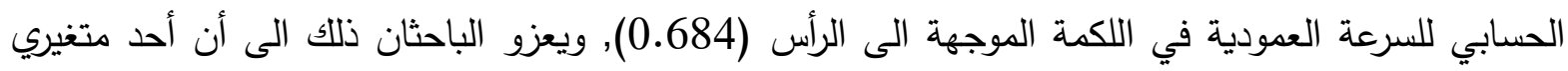

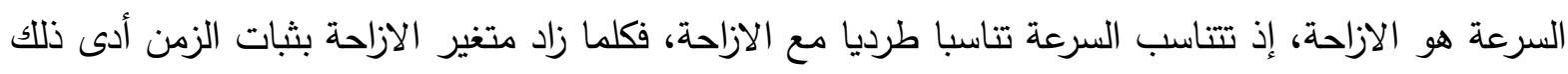

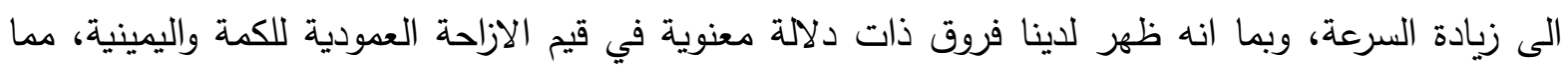

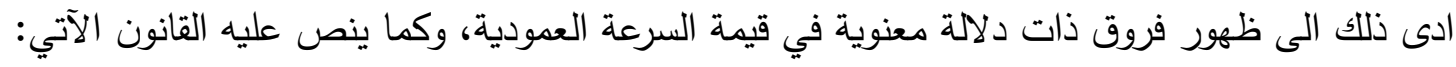

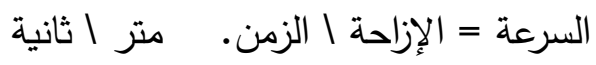

$$
\begin{aligned}
& \text { 0 - الاستنتاجات والتوصيات : } \\
& \text { ه - الاستنتاجات: }
\end{aligned}
$$

1- ظهور العديد من الفروقات المعنوية في قيم زوايا مفاصل وأجزاء الجسم بين اللكمة المستقيمة اليمينية الموجهة الى الرأس والبطن.

ץ- ظهور العديد من الفروقات المعنوية في قيم السرعة الزاوية لدفاصل الجسم بين اللكمة اليمينية الموجهة الى الرأس والبطن.

ז- ظهور فروقات ذات دلالة معنوية في قيم متغيرات الازاحة العمودية بين اللكمة المستقيمة اليمينية الموجهة الى الرأس والبطن.

ـ - ظهرت جميع الفروق المعنوية ولكافة المتغيرات قيد الدراسة لمصلحة اللكمة المستقيمة الموجهة الى منطقة البطن، وهذا يدل على ان اللكمة المستقيمة اليمينية الموجهة الى البطن كانت اكثر فاعلية الى منطقة اللكم من الناحية الميكانيكية 


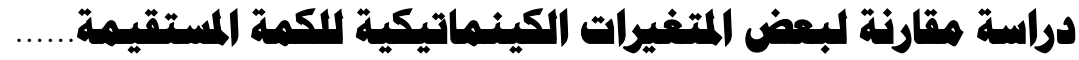

ه- كان هناك دور كبير لمتغير زاوية الورك والركبة والسرعة الزاوية لهما في اللكمتين اليمينية الموجهة الى البطن من خلال

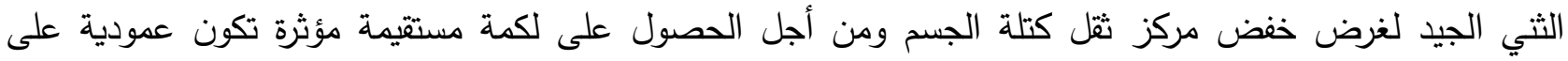
الهذف، ولتفادي اللكمات المضادة من الخضم في اثثاء النزال.

\section{• - r r التوصيات والمقترحات:}

1- مراعاة الاهتمام بالنقل الحركي للجسم من الرجلين الى الورك ثم الذراعين من اجل الحصول على التى لكمة مؤثرة في منطقة اللكم.

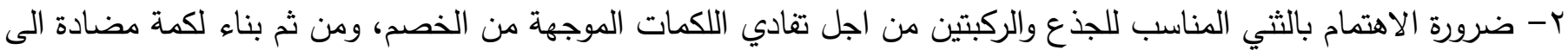

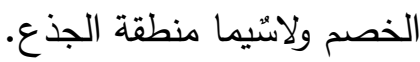

ז- الاهتمام بالفرق الزاوي لمفاصل الجسم بين وضع الاستعداد ووضع اللكم من اجل الحصول على سرعة زاوية تمكن اللاعب من توجيه ضربة مؤثرة الى الخصم.

ع- مراعاة الاهتمام عند الوضع الابتدائي بتقريب مفصل المرفقين والذراعين للدفاع ضد اللكمات الموجهة من الخضم ولغرض الحصول على سرعة زاوية عند توجيه لكمات الى الخصم. ه- ضرورة مراعاة الحفاظ على اتزان الجسم من خلال توفير قاعدة استناد جيدة للجسم، تمكن الملاكم من توجيه الضربات بحرية ولتفادي السقوط.

7- ال ضرورة الاهتمام بسرعة اللكمة. V- التأكيد على المد الكامل لمفصل الذراع عند اللكم بزمن مناسب، من أجل الحصول على مسافة كبرى وسرعة لكم فضلى. 1- اجراء دراسة تحليلية مشابهة لمتغيرات أخرى لم يتطرق اليها الباحثان. 9- اجراء دراسات تحليلية مشابهة لأنواع أخرى من اللكمات.

\section{المصـادر}

1- التكريتي، وديع ياسين وآخرون(ب/91()): الاسس التعليمية في الملاكمة، الجزء الأول، مطبعة جامعة الموصل، العراق.

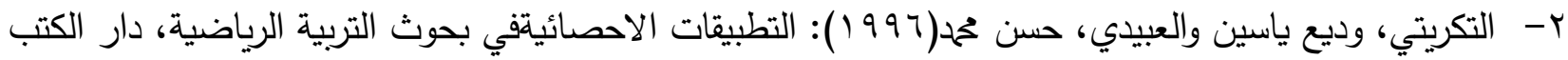
للطباعة والنشر ، جامعة الموصل.

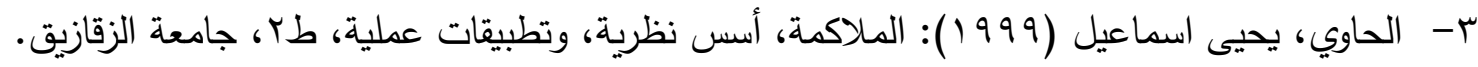

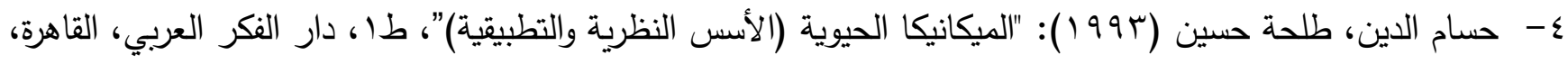

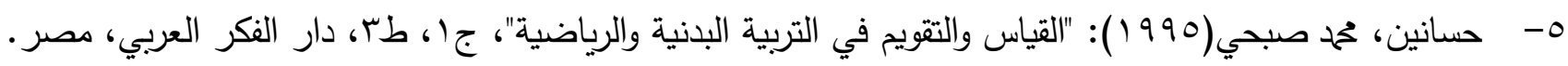

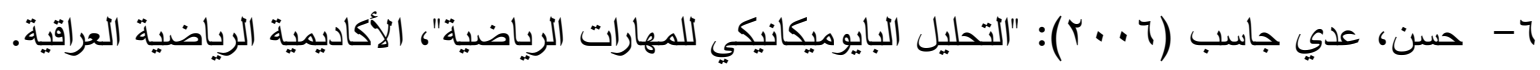

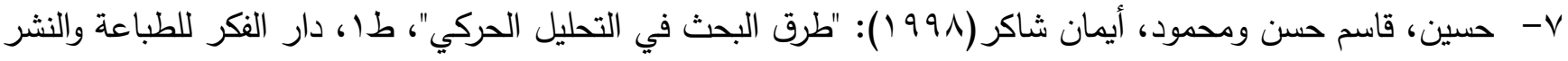
والتوزيع، عمان. 1- جيردهوخموث (9V^ () ): الميكانيكا الحيوية وطرق البحث العلمي للحركات الرياضية، ترجمة كمال عبد الحميد، دار المعارف، مصر . 


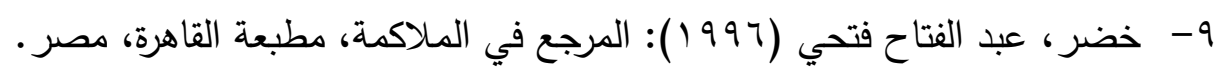
• ( -زيبار حسين طاهر (1 ( • rم) "دراسة تحليلية لبعض المتغيرات البايوكينماتيكية لمهارة اللكمة المستقيمة وعلاقتها بدقة وسرعة رد الفعل لاى الملاكمين الشباب في أقليم كوردستان" رسالة ماجستير غير منشورة، مجلس كلية التربية الرياضية، جامعة صلاح الدين. (المان. ا ا - السامرائي، فؤاد توفيق (911 ( ): “البيوميكانيك “، دار الكتب للطباعة والنشر ، جامعة الموصل.

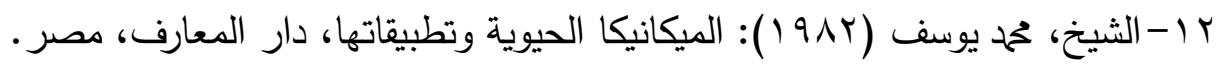

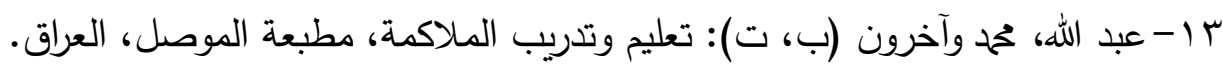
ـ ا - عبد الخالق، عصام (999 (19): "التدريب الرياضي نظريات وتطبيقات"، ط9،، جامعة الإسكندرية، مصر 0 1 - عبد المنعم،سوسن وآخرون(9VV (1)): "البايوميكانيك في المجال الرياضي" ، ج (،دار المعارف بمصر ، القاهرة .. 7 ( 1 - علاء الدين، جمال ححد(910 () ): "دراسة معملية في بايوميكانيكا الحركات الرياضية، دار المعارف، القاهرة، مصر .

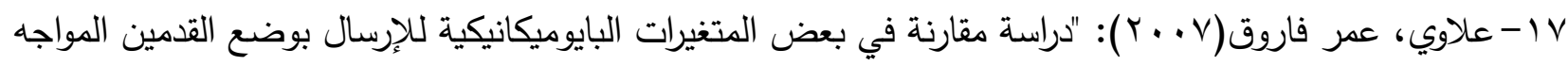
والموازي في التنس"، رسالة ماجستير غير منشورة، مجلس كلية التربية الرياضية، جامعة الموصل. 1 ا - مجيد، ريسان خريبط، وشلش، نجاح مهدي(ب9 99 ()): "التحليل الحركي"، دار الحكمة، جامعة البصرة.

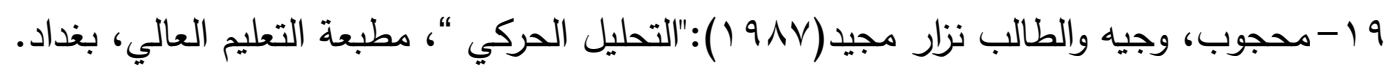
• ץ- الهاشمي، سمير مسلط (999 (99): البايوميكانيك الرياضي، طج، دار الكتب للطباعة والنشر، جامعة الموصل. المصادر الأجنبية

21- Northip John W. In addition, others (1979): Biomechanic ana lysis of sport W.M.C Brown company publishers U.S.A.

22- Bartlett, Rorer (2001): Introduction to Sport Biomechanics, E \& FN Spon, an imprint of Chapman \& Hall, USA.

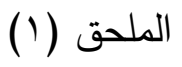

بين أسماء السادة الذين نفذوا التجربة

\begin{tabular}{|c|c|c|}
\hline الصفة & العنوان الوظيفي & 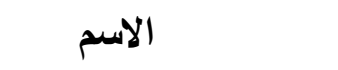 \\
\hline مشرفا & تدريسي (كلية التربية الرياضية) & د. فلاح طه حمو \\
\hline مصورا & تدريسي (كلية التربية الاساسية) & 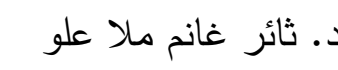 \\
\hline مساعدا & ماجستير تربية رياضية & السيد محمود هاشم محمد \\
\hline مساعدا & طالب ماجستير تربية رياضية & السيد عبد الرحمن سعيد \\
\hline مساعدا & طالب ماجستير تربية رياضية & السيد تحمد محمد \\
\hline
\end{tabular}


(r) (الملحق رقم
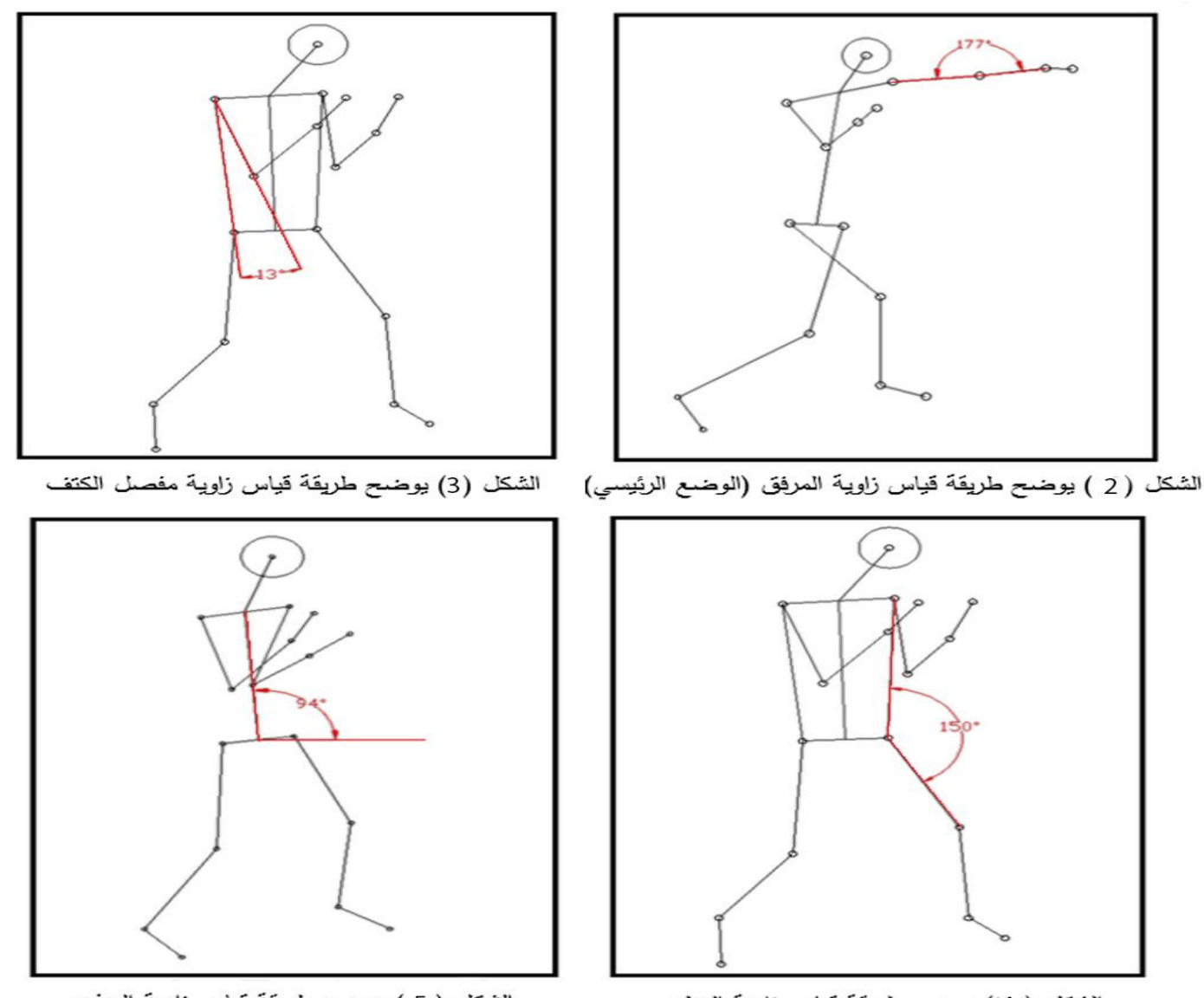

الثكن ( 5 ) يوضح طريقة قياس زاوية الجذع

الثنك ( 4 ) يوضسح طريقة قياس زاوية الوربك

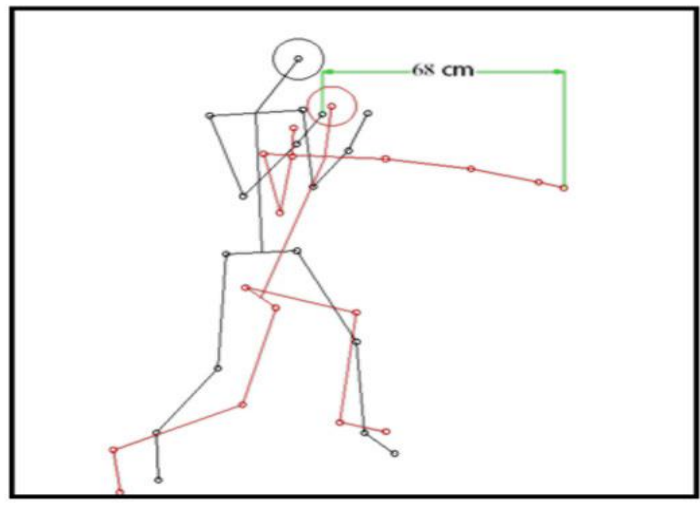

الثنك ( 7 ) يوضح طريقة قياس الازاحة الافقية

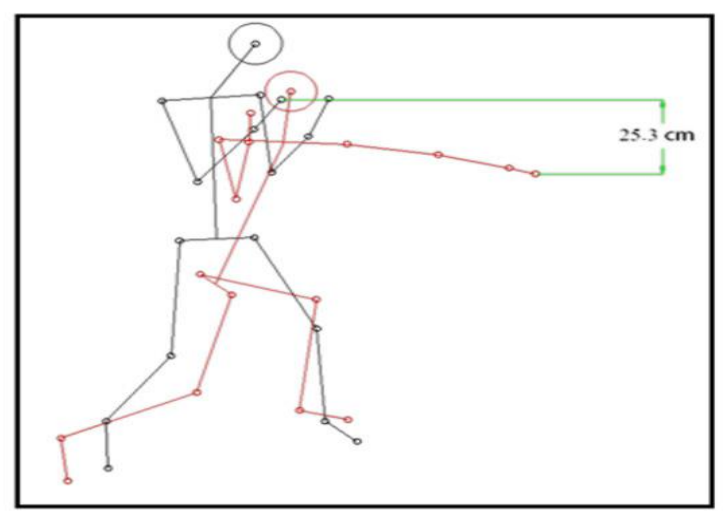

الثكن (6 ) يوضح طريقة قياس الازاحة العمودية 


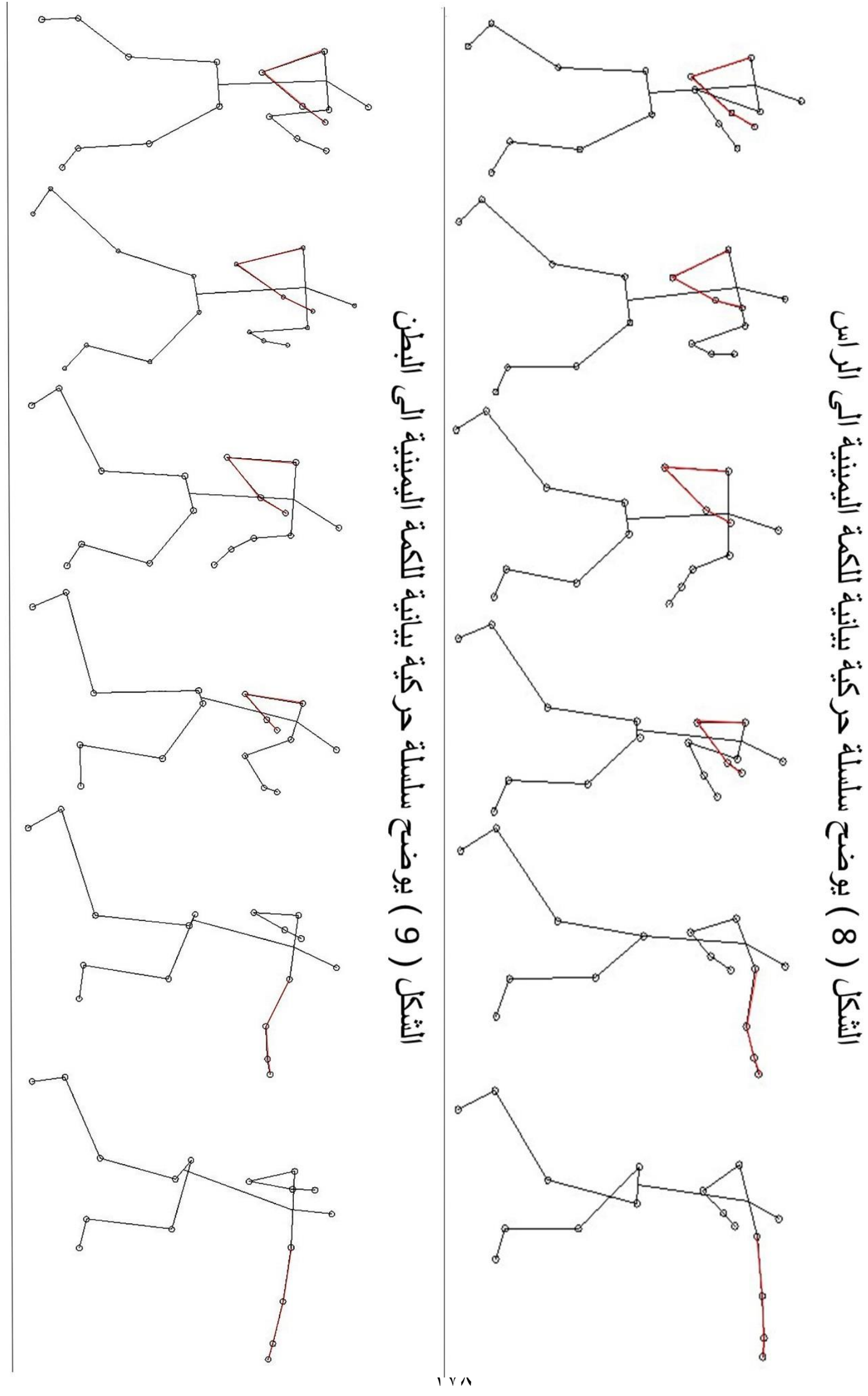

